Clemson University

TigerPrints

May 2021

\title{
Equine Gastric Ulcers; a Pilot Study: Associated Biomarkers and Polysaccharide Supplementation as a Solution
}

Peyton Victoria Svagerko

Clemson University, psvager@g.clemson.edu

Follow this and additional works at: https://tigerprints.clemson.edu/all_theses

\section{Recommended Citation}

Svagerko, Peyton Victoria, "Equine Gastric Ulcers; a Pilot Study: Associated Biomarkers and Polysaccharide Supplementation as a Solution" (2021). All Theses. 3548.

https://tigerprints.clemson.edu/all_theses/3548

This Thesis is brought to you for free and open access by the Theses at TigerPrints. It has been accepted for inclusion in All Theses by an authorized administrator of TigerPrints. For more information, please contact kokeefe@clemson.edu. 
EQUINE GASTRIC ULCERS; A PILOT STUDY: ASSOCIATED BIOMARKERS AND POLYSACCHARIDE SUPPLEMENTATION AS A SOLUTION

A Thesis
Presented to
the Graduate School of
Clemson University
In Partial Fulfillment
of the Requirements for the Degree
Master of Science
Animal and Veterinary Sciences
Peyton Svagerko
May 2021
Aristine Vernon, PhD, Committee Chair
William C. Bridges, PhD
Elliot Jesch, PhD
Shannon Pratt Phillips, PhD




\begin{abstract}
Equine Gastric Ulcer Syndrome affects roughly $90 \%$ of performance horses. The only reliable antemortem diagnostic method is endoscopy, which is an invasive process. The cornerstone of treatment is acid suppression, a cost-prohibitive option that is not viable for long-term use. The objectives of this study were to investigate the efficacy of a polysaccharide (PS) supplement on gastric ulcers in the squamous (SQ) and glandular (GL) regions of the equine stomach and identify associated serum and salivary biomarkers. It was hypothesized that severity of SQ and GL ulcers throughout the supplemental period would decrease and levels of serum and salivary proteins, as well as total antioxidant capacity (TAC), would fluctuate with ulcer scores. To test this hypothesis, 8 mature geldings were randomly assigned to a PS-supplemented (TRT) or non-supplemented (CTRL) group once they underwent ulcer induction using a modified Murray method: alternating 12- and 24-hr feed deprivations for a total of $108 \mathrm{hr}$. Following the induction, TRT horses' feed was top-dressed with 1oz of PS supplement twice daily. Horses were fed 1.0\% BW in Fescue hay (Festuca pratensis) and $0.25 \%$ BW in concentrates daily $\left(\right.$ Nutrena $^{\circledR}$ Triumph $^{\circledR}$ Fiber Plus, Cargill ${ }^{\circledR}$, Inc., Holmesville, OH) with ad libitum water access, as recommended by the NRC. Horses were housed in $3.05 \times 3.65 \mathrm{~m}$ stalls and 4 were turned out per 0.809 ha pastures from $0600-1800 \mathrm{hrs}$ and 1800 to $0600 \mathrm{hrs}$, respectively. Pastures were composed of Fescue (Festuca pratensis), rye (Lolium multiflorum), clover, and other native grasses. The experiment was divided into 3 periods: pre- (Day 0), mid- (Day 28), and post-supplementation (Day 42). Per period, endoscopic images were captured and saliva, blood, and gastric fluid samples
\end{abstract}


were collected. The effects of time and treatment were analyzed with a factorial ANOVA. All statistical calculations were performed using the software JMP. The severity of ulcer scores decreased in all horses over the 6-week timespan ( $\mathrm{P}=0.001)$, with no difference found in ulcer scores between TRT and CTRL horses in the SQ or GL regions. It is possible that the body's innate healing capacity was adequate in this study, which may have masked the treatment effect of the PS supplement. There was a correlation found between salivary $\mathrm{TAC}\left(\mathrm{R}^{2}=0.559 ; \mathrm{P}=0.005\right)$ and serum TAC $\left(\mathrm{R}^{2}=0.620 ; \mathrm{P}=0.002\right)$ and ulcer score, which may indicate a shift in oxidative stress factors as ulcers heal. The investigation of polysaccharide supplementation as a preventative measure in ulcerative and non-ulcerative horses under stress is warranted. Additionally, the exploration of other salivary and serum biomarkers to further develop a panel for preliminary screening of equine gastric ulcers should be pursued. 


\section{ACKNOWLEDGMENTS}

Thank you to BioZyme ${ }^{\circledR}$, Inc. for supplying the product and monetary gift that funded this research. I greatly appreciate Dr. Lynsey Whitacre, Dr. Ignacio Ipharraguerre, and Ana Gutiérrez Montes for their assistance with experimental design and analysis.

Dr. Alexandra Tracey and her team at Palmetto Equine Veterinary Services, thank you for performing a multitude of endoscopies and taking the time to capture quality photos of each horse's gastric abnormalities.

I am very grateful for the support from my Clemson community. Dr. Kristine Vernon has been academically guiding me for six years, and I cherish and respect her advice in and out of academia. Dr. William Bridges, my statistician, tolerated countless meetings to ensure we made the most use of the data. Thank you to my other committee members, Dr. Elliot Jesch and Dr. Shannon Pratt Phillips, for their aid in experimental design and data interpretation. Julia Gentry and the staff at Clemson University Equine Center, thank you all for your care taken in the execution of protocol.

Lastly, thank you to friends and family that have provided their support. Your unwavering faith in me, willingness to give advice, and strength to hold me accountable is a huge factor in the completion of this research. 


\section{TABLE OF CONTENTS}

\section{Page}

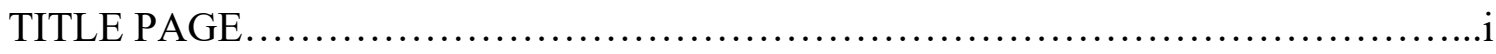

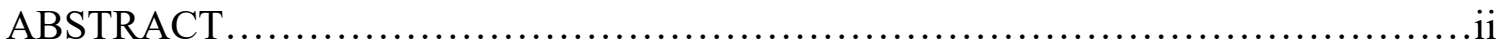

ACKNOWLEDGMENTS ......................................................

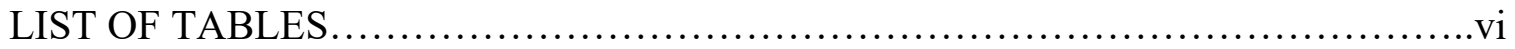

LIST OF FIGURES.........................................................

\section{CHAPTER}

I. LITERATURE REVIEW ..............................................

II. EQUINE GASTRIC ULCERS: POLYSACCHARIDE

SUPPLEMENTTION AS A SOLUTION...........................27

III. EQUINE GASTRIC ULCERS: ASSOCIATED BIOMARKERS............42

IV. $\quad$ SUMMARY .................................................. 54

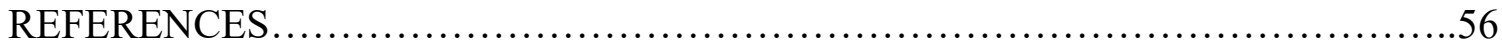




\section{LIST OF TABLES}

Table $\quad$ Page

2.1 Grading system for the squamous and glandular mucosa..................30 


\section{LIST OF FIGURES}

Figure $\quad$ Page

2.1 Gastric ulcer scores on day 0, 21, and 42 of polysaccharide supplemented (TRT; $n=4)$ versus non-supplemented horses (CTRL; $n=4)$.

2.2 Gastric ulcer scores on day 0,21 , and 42 of all experimental horses $(n=8) \ldots 33$

2.3 Squamous (SQ) versus glandular (GL) gastric ulcer scores on day 0, 21, and

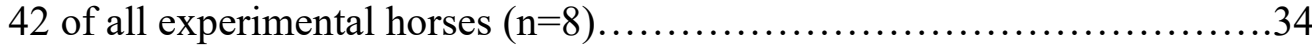

2.4a Squamous (SQ) gastric ulcer scores on day 0, 21, and 42 of polysaccharide supplemented horses (TRT; $n=4$ ) versus non-supplemented horses (CTRL;

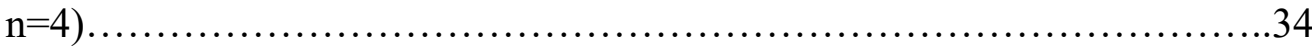

2.4b Glandular (GL) gastric ulcer scores on day 0,21 , and 42 of polysaccharide supplemented (TRT; $n=4)$ versus non-supplemented horses $(n=4)$.

2.5 Ulcer scores in various regions (margo plicatus (MP), non-margo plicatus (NMP), pylorus (P), and non-pylorus (NP)) on day 0,21 , and 42 of all experimental horses $(\mathrm{n}=8)$.

2.6 $\mathrm{pH}$ values of the proximal (P) and distal (D) regions of the equine stomach on

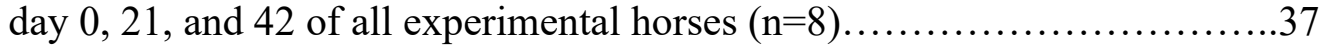

3.1 Salivary adenosine deaminase (ADA) concentrations from day 0,21 , and 42 sample collections in polysaccharide supplemented (TRT; $n=4)$ and non-supplemented (CTRL; $\mathrm{n}=4$ ) with glandular (GL) ulcers

3.2 Salivary total antioxidant capacity (TAC) concentrations in polysaccharide supplemented (TRT; n=4) and non-supplemented horses (CTRL; n=4) with glandular (GL) ulcers.

3.3 Serum total antioxidant capacity (TAC) levels in polysaccharide supplemented (TRT; $n=4)$ and non-supplemented (CTRL; $n=4)$ with squamous (SQ) ulcers

3.4 Serum adenosine deaminase (ADA) levels in polysaccharide supplemented (TRT; $n=4)$ and non-supplemented horses (CTRL; $n=4)$ with glandular (GL) ulcers. 
List of Figures (Continued)

$\begin{array}{lll}\text { Figure } & \text { Page }\end{array}$

3.5 Serum total protein (TP) levels in polysaccharide supplemented (TRT; $\mathrm{n}=4$ ) and non-supplemented horses (CTRL; $\mathrm{n}=4$ ) with glandular (GL) ulcers......51 


\section{CHAPTER ONE}

\section{LITERATURE REVIEW}

\section{Terminology}

The term Equine Gastric Ulcer Syndrome (EGUS) was first used in 1999 to describe gastric ulceration in the horse (Andrews, 1999). Termed by the Equine Gastric Ulcer Council (EGUC), EGUS is defined as the disease complex that is associated with ulceration of the esophageal, gastric, or duodenal mucosa. Misuse of this term is common and the EGUC emphasized the importance of distinguishing between diseases of the squamous (SQ) and glandular (GL) mucosa, as their pathophysiology and treatment needs differ greatly (Merritt, 2009). Thus, the term EGUS is used as an all-encompassing term to describe ulcerative and erosive diseases of the equine stomach, Equine Squamous Gastric Disease (ESGD) describes ulcerations of the SQ mucosa, and Equine Glandular Gastric Disease (EGGD) describes ulcerations of the GL mucosa. ESGD can be further categorized as primary, the more common form, or secondary. Animals diagnosed with

primary ESGD have an otherwise normal gastrointestinal (GI) tract and those diagnosed with secondary ESGD have an underlying gastric abnormality. Specifications of EGGD are lacking, thus it is recommended to diagnose ulcerations according to their anatomical location (cardia, fundus, antrum, or pylorus) and the appearance of the lesion (Sykes et al., 2015a). 


\section{Pathophysiology}

Squamous mucosa

The degree that stratified SQ mucosa extends from the esophagus into the stomach varies between domestic species. In horses, it is the proximal one half of the stomach, which is histologically composed of 4 major zones: stratum corneum, stratum transitionale, stratum spinosum, and stratum basale. No mucus cells are present within these layers. The main function of the metabolically active layers below the stratum corneum is active $\mathrm{Na}^{+}$transport, operated by $\mathrm{Na}^{+}-\mathrm{K}^{+}$ATPases (Chien and Stevens, 1972). The SQ mucosa's high electrical resistance aids in barrier function, prohibiting penetration by large molecules. There is a minimal barrier of tight junctions present in the stratum corneum, which is supported further by the principal barrier of the stratum spinosum. Once past the latter barrier, there is minimal resistance to the penetration of large molecules (Orlando, 1991). Weak acids, such as short chain fatty acids (SCFA) that result from microbial digestion of carbohydrates, are also considered weak electrolytes. This allows their rapid diffusion across the mucosal barrier as luminal $\mathrm{pH}$ decreases, which in swine has been found to irreversibly insult the current of $\mathrm{Na}^{+}$transport that results in a decrease in electrical resistance, thus indicating the reduction of barrier function. The process of injury to SQ mucosa via SCFA progresses from penetration of the outer barrier, acidification of the underlying transport cells, elimination of the short circuit current, cell swelling, to a fall in electrical resistance. Contrarily, injury from a strong acid, such as $\mathrm{HCl}$, results in erosion of outer layers of the mucosa, acidification of 
transporting cells via exposure to $\mathrm{H}^{+}$, diminished cell volume regulation, cell swelling, and eventual necrosis (Argenzio, 1999; Carney et al., 1981).

\section{Glandular mucosa}

The pathophysiology of EGGD is less understood, as the mucosa of the GL region functions differently than the SQ mucosa. The GL mucosa consists of a mucusbicarbonate layer on the epithelium surface, which is responsible for titrating incoming luminal $\mathrm{H}^{+}$ions to $\mathrm{CO}_{2}$ and $\mathrm{H}_{2} \mathrm{O}$ (Flemstrong, 1994). Unlike SQ mucosa, GL mucosa has varying capacity to heal by migration of healthy tissue to the site of injured tissue, a process denoted as restitution (Silen, 1987). Another difference between the mucosa is the protective properties of prostaglandins for the GL region, which aid in increased blood flow as well as mucus and bicarbonate secretion (Orlando, 1991). Under normal physiological health, the GL mucosa is constantly exposed to acidic pH levels (1-3) and has the capacity to function in this condition. Thus, EGGD occurs when the natural barriers of the GL mucosa are broken down and defense mechanisms fail. These mechanisms that contribute to the breakdown have not been elucidated in the horse and are of interest (Merritt et al., 2003).

The role of bacteria in EGGD is controversial. It is unknown whether gastric bacteria and pathogens play a role in GL ulceration as they do in the SQ region. In some studies, horses affected by EGGD had the presence of Helicobacter-like organisms (Contreras et al., 2007; Fox, 2002), where in others there was failure of identification (Husted et al., 2010; Martineau et al., 2009). 
The role of non-steroidal anti-inflammatory drugs' (NSAIDs) cause in EGGD is also controversial. At doses 50\% higher than recommended flunixin, phenylbutazone, and ketoprofen have proven to have ulcerogenic capacity (Cg et al., 1993). However, when administered at clinical doses for 15 days, phenylbutazone and suxibuzone did not induce gastric ulcers (Andrews et al., 2009).

\section{Prevalence}

The prevalence of gastric ulceration varies with breed, use, level of training, as well as between ESGD and EGGD (Andrews et al., 2009). Thoroughbreds represent the highest portion of horses diagnosed with ESGD, affecting 37\% of untrained and $80-100 \%$ of those who undergo race training for 2-3 months (Begg and O'Sullivan, 2003; Murray et al., 1996; Vatistas et al., 2010). Similarly, the percentage of ESGD increases from 44\% in non-training to $87 \%$ with training in Standardbred horses (Dionne et al., 2003; Jonsson and Egenvall, 2006; Rabuffo et al., 2002). Additionally, around 17-58\% of show/sport horses and $37-59 \%$ of pleasure horses are affected (Hartmann and Frankeny, 2003; Luthersson et al., 2009a; McClure et al., 1999; Murray et al., 1989; Niedźwiedź et al., 2013). Outside of competition season, around $48 \%$ of endurance horses have been found to be affected by ESGD, while 66-93\% of those in the midst of competition season are affected, with a higher rate in the elite horses (Nieto et al., 2004; Tamzali, 2011). Horses 
that do not commonly travel or compete have an $11 \%$ prevalence of ESGD (Chameroy et al., 2006).

Research on the prevalence of EGGD is not as thorough. Prevalences between 47\% and 65\% have been reported in Australian Thoroughbred horses and between 16\% of non-competitive endurance horses and $27-33 \%$ of competitive endurance horses (Begg and O'Sullivan, 2003; Nieto et al., 2004; Sykes et al., 2015b; Tamzali, 2011). In the United Kingdom, a reflective study found 54\% of 191 leisure horses and 64\% of 493 sport horses had EGGD (Hepburn, 2005). Similarly, in 2 separate studies, 57\% of horses used for a variety of purposes were reported to have EGGD (Husted et al., 2010; Luthersson et al., 2009a). For each of the previously mentioned studies involving EGGD, the majority of lesions were found in the pyloric antrum.

\section{Risk Factors}

\section{Nutrition}

There is conflicting evidence surrounding the capability of pasture turnout to reduce the risk of EGUS. While grazing, the horse's continuous secretion of saliva and influx of ingesta act to buffer stomach acid. When feed access is intermittent, gastric $\mathrm{pH}$ drops, exposing the SQ mucosa to an acidic environment (Buchanan and Andrews, 2004). One particular study involving Thoroughbred horses in training found that horses in turnout were less likely to have ESGD, and those turned out with the company of other horses had an even lower risk (Lester et al., 2007). On the contrary, a separate study on Thoroughbred horses in training found no effect of quality of pasture or time at pasture 
on ESGD risk (Bell et al., 2007). An additional study's findings suggested that pasture turnout on its own might not affect gastric $\mathrm{pH}$. This was based on a lack of intragastric $\mathrm{pH}$ difference in horses fed ad libitum grass hay and grain twice per day $(1 \mathrm{~kg} / 100 \mathrm{~kg} / \mathrm{d})$ when they were housed in a grass paddock, in a stall on their own, or in a stall with an adjacent companion (Husted et al., 2008).

Free access to fibrous feed or frequent forage feeding is widely considered to reduce the risk of gastric ulceration (Sykes et al., 2015a). At a minimum, those receiving hay should be offered 1.5\% of their bodyweight per day (Videla and Andrews, 2009). Horses and ponies that are overweight and at risk of EGUS should be offered hay that is mature with a low energy content. If there is no low-energy hay available, a mixture of high-quality hay and straw can be offered, but straw should not be the only forage provided, as it is suggested that forage type is an important factor in the prevention and management of EGUS. When attempting to raise gastric $\mathrm{pH}$ and decrease peptic injury, a diet consisting of alfalfa hay and grain was found to be more effective than a diet absent of grain and consisting solely of brome grass hay or coastal Bermuda hay (Lybbert et al., 2007; Nadeau et al., 2000). Adding to that suggestion, there is an increased likelihood of ESGD when straw is the sole forage provided (Luthersson et al., 2009a). In addition, the impact of forage feeding in the absence of alternate risk factor reduction might not be as effective as previously thought. In one study, both the number and severity of ESGD lesions were greater in the high-fiber group in comparison with the group fed an isoenergetic diet (Boswinkel et al., 2007). It has also been found that the likelihood of 
ESGD is increased when time intervals between forage meals increases (Luthersson et al., 2009a).

Consistently, it has been found that there is an increased risk of ESGD in animals working at various levels of intensity that have an increased starch/grain intake. When non-exercising horses are stabled and fed grain at $1 \%$ of $\mathrm{BW}$ one hour before hay is given, there is a notable increase in ulceration (Frank et al., 2005). Furthermore, there is an approximately two-fold increased risk of ESGD in horses fed amounts exceeding $2 \mathrm{~g} / \mathrm{kg} \mathrm{BW}$ of starch intake per day (Luthersson et al., 2009a). Horses maintaining a 6 $\mathrm{kg} / \mathrm{d}$ diet of grain that entered an artificial training regimen and stabling after being removed from pasture developed ESGD within 14 days (Vatistas et al., 1999). High concentrate diets are typically high in non-structural carbohydrate, such as starch. In the process of starch digestion by fermentation via residential bacteria, VFAs are produced. The presence of VFAs in a stomach with a $\mathrm{pH} \leq 4$ directly causes acid damage to SQ mucosa (Nadeau et al., 2003). Diets higher in protein and calcium (alfalfa hay/grain) have resulted in less severe gastric ulcers when compared to a low protein and calcium diet (brome grass hay), indicating a potential protective effect of alfalfa hay on the SQ mucosa (Buchanan and Andrews, 2004).

Another factor increasing a horse's risk of developing EGUS is intermittent access to water. It has been shown that horses without water access are over 2.5 times more likely to have EGUS than those with ad libitum water access (Luthersson et al., 
2009a). Interestingly, this risk factor applied to all portions of the stomach, as opposed to solely affecting the SQ mucosa.

\section{Exercise}

The relationship between training or racing and prevalence is significant, as approximately $60-90 \%$ of performance horses suffer from EGUS (Buchanan and Andrews, 2004). When the horse is at a gait faster than a walk, the increased intraabdominal pressure and decreased stomach volume causes acidic gastric contents to push up to the level of the SQ mucosa, resulting in prolonged exposure of the mucosa to acidic gastric contents (Lorenzo-Figueras and Merritt, 2002). Daily exercise may contribute to increased exposure of the SQ tissue to acidic gastric contents, explaining the increased prevalence of gastric ulcers in horses in training (Buchanan and Andrews, 2004). Additionally, significant association has been found between increased interval training for long durations and increased prevalence of lesions, lesion severity, and number of lesion sites (Murray et al., 1996; Orsini et al., 2009; Roy et al., 2005). In elite endurance horses, there is a direct correlation between distance of ride and severity of ESGD (Tamzali, 2011).

\section{Transportation}

The increased incidence of EGUS in horses that are regularly transported is likely due to decreased access to feed and water. Additionally, transportation is associated with dehydration and immune suppression, potentially contributing to overall health decrease (Watson, 2002).

\section{Stall confinement}


The influence of stall confinement on the development of gastric ulcers is likely multifactorial, as intermittent feeding and restriction of exposure to other horses are common in those that are housed in stalls. However, one study did find that horses housed in pastures have a decreased prevalence when compared to horses confined to stalls (Fiege et al., 2002).

\section{Nonsteroidal anti-inflammatory drugs}

It has been proven that various NSAIDs cause gastric ulcers in horses (MacAlliser and Sangiah, 1993). Abundant studies in Thoroughbred racehorses have contradicted this, each coming to the conclusion that the use of NSAIDs in racehorses is not a risk factor for EGUS (Johnson et al., 1994; McClure et al., 1999; Murray et al., 1996; Rabuffo et al., 2002; Vatistas et al., 2010). However, another study found that NSAIDs did cause ulcers of the GL mucosa and increased the severity of ulcers of the SQ mucosa (MacAlliser et al., 1992). NSAIDs are thought to have a greater negative impact on GL mucosa due to their role in prostaglandin inhibition, which results in decreased mucosal blood flow, decreased mucus production, and increased $\mathrm{HCl}$ secretion. The regulation of acid production, $\mathrm{Na}^{+}$transport, and mucosal blood flow by prostaglandins is crucial to GL mucosal integrity, with adequate blood flow likely being the most influential. Its aid in the removal of diffused $\mathrm{H}^{+}$ions through the mucus layer is critical (Barr, 2001; Murray, 1991).

\section{Helicobacter spp}

There are controversial findings concerning the influence of Helicobacter pylori on the development of gastric ulcers in horses. One study was able to isolate H. pylori 
DNA from both the SQ and GL mucosa of seven horses with ulcers, while other postmortem reports of horses with and without EGUS lacked any presence of related organisms (Johnson et al., 1994; Scott et al., 2001). Nevertheless, adjunctive therapies along with acid suppression may be beneficial for the treatment of gastric ulcers in horses, as it is such in other species.

\section{Clinical Signs}

Individual cases of EGUS often present with a large range of vague clinical signs. The most seen at the population level is reduced appetite and poor body condition. It is common that behavioral inconsistencies such as nervousness, aggression, and selfmutilation occur alongside ulcer presence. Considering the numerous factors that play a role, it is fair to say EGUS might result in reduced performance, but other components should also be addressed. It is not advisable to diagnose EGUS via clinical signs, but to definitively diagnose the syndrome via endoscopy (Scott et al., 2001).

\section{Colic}

There is evidence suggesting that gastric ulcers are associated with an increased likelihood of colic and postprandial abdominal upset (Murray, 1992; Murray et al., 1989; Sandin et al., 2000; Vatistas et al., 2010; Videla and Andrews, 2009). In one study, it was reported that $83 \%$ of horses with recurrent colic had gastric ulcers after undergoing suppressive acid treatment (Murray, 1992). Additionally, a study found that 3.5\% of horses that exhibited colic in the preceding month had ESGD and another reported that $49 \%$ of horses presenting acute colic had ESGD (Vatistas et al., 2010). In the latter study, it was also seen that colicking horses that were medically managed had a higher rate of 
ESGD in comparison to those that underwent surgical management (Dukti et al., 2006). Though uncertain, the difference in rates of ESGD between the two groups might be attributable to medically-managed horses undergoing longer periods of fasting (Berschneider et al., 1999; Murray, 1996).

\section{Poor coat condition}

Results concerning an association between poor hair coat and gastric ulceration are contradicting. There have been studies that found statistical association between the two, while there have also been studies that failed to identify an association (Dionne et al., 2003; le Jeune et al., 2009; Vatistas et al., 2010).

\section{Diarrhea}

There is no definitive cause-and-effect relationship between diarrhea and gastric ulceration, though it has been reported as a clinical sign in adult horses (Murray et al., 1989). Moreover, it is likely that when there is an association between diarrhea and gastric ulceration, there is a wider disease process occurring (Sykes et al., 2015a).

\section{Stereotypical behaviors}

Commonly, horses demonstrating altered or stereotypic behavior are likely to present gastric ulcerations (Andrews and Nadeau, 1999; Murray et al., 1989). For instance, competition horses with a nervous disposition tend to present ESGD more often than quiet, normally-behaved horses (McClure et al., 1999). In addition to nervousness, behavioral changes may include aggression and self-mutilation, which are behaviors such as biting, stomping, and kicking (McDonnell, 2008). Some data from racehorses has shown contrary results concerning a relationship between nervousness and ESGD, but 
interestingly showed correlation between aggression and ESGD (Lester et al., 2007). Additionally, there is a correlation between cribbing and ESGD, though the biological mechanism behind it is uncertain (Nicol et al., 2002).

\section{Decreased performance}

While poor performance is one of the most influential signs of ESGD, its investigation is lacking. The particular question is if gastric ulcers directly cause poor performance, rather than indirectly due to other clinical signs such as reduced appetite or weight loss. It is most likely that reduced performance is linked to gastric pain (Andrews, 2008). Ulcerations of the SQ mucosa in horses are similar to lesions that cause heartburn or gastroesophageal reflux disease (GERD) in humans. In one study it was found that $58 \%$ of elite athletes suffering from GERD reported upper GI pain during exercise, with a proportional increase with intensity ( $\mathrm{Lj}$ and $\mathrm{Df}, 1985)$. Additionally, human runners with GERD experience decreased time to exhaustion when compared to runners without the disease (Rodriguez-Stanley, 2006).

In racehorses, there has been limited research to provide an association between performance and the presence of ulcers. Performance measurements vary from trainer observation to objective physiologic responses through treadmill testing. It has been found that, independent of the quantity and severity, there is an association between poor performance and ESGD (Vatistas et al., 2010). Similar results have been found concerning Standardbred racehorses, showing an association between ESGD presence and reduced performance (Jonsson and Egenvall, 2006). A small trial consisting of 4 Thoroughbred horses that presented with gastric ulcers as the only abnormal factor found 
that there was improved performance with omeprazole treatment (Franklin et al., 2008). Within poor performance, it is postulated that abdominal pain caused by gastric ulcers might affect stride length and ventilation. Intermittent feed deprivation was applied to a population of horses in order to induce gastric ulcers, followed by half of the study population receiving omeprazole treatment and half receiving no treatment. With incremental treadmill exercise testing, physiological responses were recorded, and it was found that treatment horses had increased time to fatigue and longer stride length when compared to untreated horses (Nieto et al., 2009).

\section{Diagnostics}

Endoscopy is the only reliable antemortem method of diagnosing EGUS.

Preparation for endoscopy includes feed and water restrictions, as well as sedation. If necessary, before alterations to the gastric environment are made, stomach fluid samples are collected via aspiration. During the endoscopic procedure, the stomach is distended by the insufflation of air through the endoscopy biopsy channel until the SQ and GL regions of the gastric mucosa are visible. Gastric contents are thoroughly rinsed from the stomach surface using tap water flushed through the biopsy channel. Throughout the endoscopy, images are captured and digitized with a portable personal computer. At the conclusion of this procedure, the endoscope is withdrawn, and horses are appropriately recovered from sedation. When performing endoscopy, visualization of the entire stomach is crucial as the presence or absence of ESGD or EGGD cannot be used to predict the incidence of the other. 
Currently, there are no definitive hematological or biochemical markers found to reliably aid in the diagnosis of EGUS. Though the diagnostic accuracy is not clinically reported, sucrose permeability shows promise for a noninvasive diagnostic method of gastric ulcers (Hewetson et al., 2006; O'Conner et al., 2004). There have been attempts to correlate gastric ulcer presence with fecal albumin or hemoglobin, however no significant association has been found (Pellegrini, 2005; Sykes et al., n.d.).

\section{Ulcer Grading}

After ulcer presence is identified by endoscopy, severity of the lesions must be assessed. There are several methods of assigning ulcer grades, the most common being one that describes the mucosal appearance as well as anatomical location. Grading scales range from 0-3 to 0-10 in various publications (Andrews et al., 1999; Murray et al., 1996). The EGUC recommends utilizing the existing 0-4 scoring system to be used for ESGD and EGGD in order to provide clinical and research uniformity. The importance of stating the anatomical location, distribution, and appearance of lesions in the GL portion of the stomach has been emphasized, as the use of a definitive grading scale is controversial. Thus, the grading of the ulcers initially indicates whether the horses have ESGD or EGGD. Following this, lesion scores are assigned and range from 0-4 for each of the ulcer types. For ESGD, 0 indicates the epithelium is intact and there is no appearance of hyperkeratosis, 1 indicates the mucosa is intact but there are areas of hyperkeratosis, 2 indicates small, single, or multifocal $(<5)$ superficial lesions, 3 indicates large single deep, or multiple ( $\geq 5$ ) focal superficial lesions, and 4 indicates extensive lesions with areas of apparent deep ulceration. For EGGD, 0 indicates the epithelium is 
intact and there is no evidence of hyperemia, 1 indicates the mucosa is intact but there are areas of hyperemia, 2 indicates small, single, or multifocal $(<5)$ superficial lesions, 3 indicates large single deep or multiple $(\geq 5)$ focal superficial lesions, and 4 indicates extensive lesions with areas of apparent deep ulceration (Sykes and Jokisalo, 2014, p. 1).

\section{Treatment and Prevention}

Commonly, empiric treatment is administered when endoscopy is unavailable. Due to cost and importance of distinguishing between ESGD and EGGD, treatment without definitive diagnosis is not recommended. However, if treatment is administered empirically and there is a failure to respond, endoscopy should still be performed to rule out gastric disease.

\section{Pharmaceutical Therapy}

Antacids

Antacids are mainly effective through neutralizing stomach $\mathrm{HCl}$, but aluminumcontaining formulas have potential for added mucosal protective effects through the stimulation of prostaglandin production. There are mixed conclusions on their efficacy of controlling stomach pH (Szelnenyi et al., 1989). Varying compositions and administrations of aluminum hydroxide and magnesium hydroxide were found to have short-term effects on stomach pH (Clark et al., 1996; Murray and Grodinsky, 1992). It has been gathered that efficacy of antacid administration seems dependent on frequent, large doses, which may impact electrolyte absorption. There is slight symptomatic relief from antacids, but the longevity of their efficacy is poor. The effects last $\leq 2$ hours, therefore its use as a sole therapeutic agent is unjustified (Clark et al., 1996; Murray and 
Grodinsky, 1992). Thus, administering antacids may be beneficial for relieving clinical signs of EGUS, but are not likely effective in healing gastric ulcers (Buchanan and Andrews, 2004).

Histamine type 2 receptor antagonists

Acid secretion from parietal cells is stimulated by histamine. Histamine type 2 $\left(\mathrm{H}_{2}\right)$ receptor antagonists bind to the histamine receptor, thus decreasing acid secretion by blocking histamine from attaching. The $\mathrm{H}_{2}$ receptor antagonist may also be proficient in inhibiting gastric acid secretions caused by gastrin and acetylcholine (Brunton, 2000). Cimetidine and ranitidine are the most reviewed $\mathrm{H}_{2}$ receptor antagonists. Cimetidine is not extremely effective and ranitidine is more commonly used, as it is four times more potent (Ross et al., 1981). Efficacy of ranitidine is dose-dependent, and in certain cases may suppress acid output and maintain a stomach pH of 4.6 (Holland et al., 1997;

Johnson et al., 2001; Murray and Schusser, 1993).

\section{Proton pump inhibitors}

Currently, the cornerstone of gastric ulcer treatment is acid suppression in both ESGD and EGGD. Omeprazole is the most well-reviewed proton pump inhibitor used for the treatment of gastric ulcers in horses. It works by impairing the $\mathrm{H}^{+}-\mathrm{K}^{+} \mathrm{ATPase}$ pump that secretes $\mathrm{HCl}$ (Clark et al., 1996). Currently, omeprazole it is the only FDA-approved drug for EGUS treatment and is usually the drug of choice. It is effective only when formulated to withstand the acidic environment of the stomach to avoid premature degradation. Common methods of obtaining this formula include a buffered paste or enteric coated granules, with contrasting evidence on which is superior (Birkmann et al., 
2014). Overall, findings suggest that doses of omeprazole, either buffered or enteric coated, are efficacious and warrant consideration.

When introduced to an acidic environment, omeprazole is activated to a sulfonamide derivative and subsequently binds reversibly to $\mathrm{H}^{+}-\mathrm{K}^{+}$ATPase in parietal cells. This results in the inhibition of $\mathrm{H}^{+}$ion transport into the cell, hence its classification as a proton pump inhibitor (Plumb, 2002). Omeprazole is metabolized in the liver and excreted in the urine and bile, therefore horses with significant liver disease may metabolize the drug at different rates. In other species, long-term administration has not caused clinical, hematologic, or biochemical alterations, however, it has caused a reversible gastric mucosal hypertrophy (Sundell and Nillsson, 1986), hyperplasia of enterochromaffin-like (ECL) cells, and gastric carcinoid tumors (Tielemans et al., 1989). In horses, no significant side effects have been reported when treated for up to 90 days.

The required duration of acid suppression to allow for healing of ESGD and EGGD has not been defined in horses. Previous literature suggests that once daily administration of omeprazole results in 24 hours of acid suppression, but recent studies have countered this belief with finding acid suppression as short as 12 hours in some animals (Daurio et al., 1999; Jenkins et al., 1992). Even so, based on several studies, 12hour acid suppression is sufficient for ESGD treatment. Another consideration to be made is the duration of treatment. The standard omeprazole treatment is 28 days, but it has been found that healing of ESGD has occurred in 21 days (Murray et al., 1997). Even within the standard 28-day treatment, it is important to note that only approximately 70 80\% of ESGD lesions will heal (Andrews et al., 1999; Doucet et al., 2003; Murray et al., 
1997). Thus, follow-up endoscopies must be continued until treatment has ceased to ensure proper healing has occurred.

Treatments pertaining specifically to EGGD have not been considered until recently. The difference in the healing process of the SQ and GL tissue warrant treatment investigation. In a recent study where 28-35 days of omeprazole treatment was administered, only $25 \%$ of EGGD lesions healed whereas ESGD lesions had a 78\% healing rate (B. W. Sykes et al., 2014a, 2014b; Sykes et al., 2015b). It is possible that EGGD lesions might require longer treatment periods. In humans, the duration of treatment for GL ulcerations depends on the cause of the injury, but is typically 8 and 12 weeks for $84 \%$ and $100 \%$ healing rates for ulcers induced by NSAIDs (Lancaster-Smith et al., 1991). Healing rates of EGGD have been observed to be around the same time frame; however, clinical trials tailored to this topic are lacking (Sykes et al., 2015a). In addition to the possibility of longer treatment duration requirements, the role of bacteria in EGGD should be examined. If bacteria play a factor in the development of EGGD, omeprazole monotherapy might be inadequate, and the use of adjunctive therapies should be considered. In humans, ulcerations associated with $H$. pylori call for triple treatment, including antimicrobials. This results in healing rates $>80 \%$ (Malfertheiner et al., 2009). Theorizing from this, antimicrobial treatment in the horse for EGGD is popular. However, antimicrobials do not improve healing of non H. pylori ulcerations in humans, therefore no evidence exists to support their use in horses for healing EGGD (Malfertheiner et al., 2009; Sykes et al., 2014). 


\section{Coating or binding agents}

The use of mucosal protectants for the treatment of EGGD is warranted given the suggested role of mucosal defense failure in the development of GL lesions. The mucosal protectant backed by the most research is sucralfate, which functions by adhering to ulcerated mucosa as well as stimulating mucus secretion, prostaglandin $E_{2}$ synthesis, and blood flow, all of which are beneficial to the healing process of EGGD (Murray, 2017). The hydroxyl aluminum salt of sucrose octasulfate becomes adhered due to the negative charge of the ulcer bed, resulting in the secretion of bicarbonate that buffers $\mathrm{HCl}$ (Borne and MacAllister, 1993). Additionally, once in the stomach, sucralfate is converted to a sticky amorphous mass that may aid in the inhibition of $\mathrm{H}^{+}$diffusion into the ulcer. The efficacy of sucralfate alone is extremely variable. In combination with omeprazole treatment, it has resulted in healing rates of $67.5 \%$ in the pyloric antrum, which is one of the most common and resistant areas of ulceration in the GL region of the stomach (Hepburn and Proudman, 2014).

\section{Antibiotics}

In humans, ulcerations associated with $H$. pylori call for triple treatment including antimicrobials. This results in healing rates $>80 \%$ (Malfertheiner et al., 2009). Combination therapy has been most effective in other species, pairing acid suppressive therapy with antibiotics (Hall, 2000). Theorizing from this, antimicrobial treatment in the horse for EGGD is popular. However, antimicrobials do not improve healing of non $H$. pylori ulcerations in humans, therefore no evidence exists to support their use in horses for healing EGGD (Malfertheiner et al., 2009; Sykes et al., 2014). 


\section{Nutraceutical Therapy}

\section{Pectin-lecithin complex}

The ease of use and availability of nutraceuticals are appealing, but they provide mixed results. Increased total mucus concentration in gastric juice has been found in studies investigating pectin-lecithin complexes (Koeller, 2010). Contradicting this, two studies involving pectin-lecithin complexes did not find a protective effect in horses with ESGD (Venner et al., 1999). More recently, showing promise for treatment of ESGD and EGGD simultaneously is a combination of an antacid (magnesium hydroxide), a pectinlecithin complex, and Saccharomyces cerevisiae (Sykes et al., 2014).

\section{$B$ vitamin complex}

There has been promise of ESGD management by a feed supplement consisting of B vitamins combined with organic salts as well as possible EGGD prevention via sea buckthorn berries (Hellings and Larsen, 2014; Huff et al., 2012).

\section{Corn oil}

Arachidonic acid precursors, such as linoleic acid, have been investigated for their ability to increase endogenous prostaglandin production and decrease maximally stimulated acid output (Grant et al., 1988; Mandel et al., 1994; Schepp et al., 1988). There is interest in the potential role of prostaglandins, specifically those of the E series, to provide mucosal protection and potential therapeutic value as they have been found to have anti-ulcer properties (Lanza, 1989; Wilson, 1988). In studies involving humans and rats, it has been found that dietary supplementation with linoleic acid increased the prostaglandin $\mathrm{E}_{2}$ concentration in gastric secretion and reduced acid output (Grant et al., 
1988; Schepp et al., 1988). Additionally, rats induced via cold, restraint, and ethanol administration had significantly reduced mucosal lesions when fed a linoleicsupplemented diet (D and A, 1991; Mandel et al., 1994; Schepp et al., 1988). Corn oil supplementation is an economical approach to management of the equine GL mucosa, especially when injury is caused by NSAID usage.

\section{Gastrocure}

Gastrocure is a natural feed supplement composed of Plantago ovate (Fleawort extract), Trigonellafoenum-graecum (Fenugreek extract), Aloe Vera, and Glycyrrhiza labra (Licorice extract). The bulk of composition is alfalfa hay, soybean kernel, saccharose, calcium carbonate, oils and vegetable fats, magnesium hydroxide, and methyl-sulphonyl-methane. In Italy, Stucchi Luca et al. (2017) administered Gastrocure for 30 days to evaluate the efficacy of the product as a sole treatment option for equine gastric ulcerations in sport horses in training. The supplement was found to be effective in reducing gastric ulcer score and severity. Positive results may be due to various components of the supplement, including alfalfa hay, magnesium hydroxide and calcium carbonate, due to their buffering effects (Clark et al., 1996; Husted et al., 2008). Other nutrients that may have had added a protective effect for the gastric mucosa include threonine, Glycyrrhiza labra, aloe vera, antioxidant factors and mucilages. At the gastricenteric level, the amino acid threonine is involved in mucus production. Several studies have reported the efficacy of licorice in providing anti-ulcerogenic activity by suppressing acid secretion and increasing mucus secretion, along with promoting the release of prostaglandin $E_{2}$ (Guslandi, 1985; Kassir, 1985). Additionally, it has been 
reported that flavonoid, a content of licorice, could inhibit proton-pump activity in the GL mucosa (Beil et al., 1995; Kassir, 1985). Due to studies on humans and rats, the antiulcerogenic capacity of aloe vera has been hypothesized due to its anti-inflammatory, cytoprotective, and mucus-stimulating effects (Langmead et al., 2004). Antiinflammatory effects were also found in horses (Lans et al., 2006). It is further hypothesized that aloe vera may act to increase the perfusion of gastric mucosa, which results in vasoconstriction and promotes angiogenesis, facilitating the healing of ulcers. Finally, mucilages which include pectin, guar, psyllium, and fenugreek in this case, form a viscous gel when in an acidic environment, protecting the mucosa from the harsh effects of the acidity (Ferrucci et al., 2003; Lans et al., 2006; Murray and Grady, 2002).

\section{Polysaccharide supplement}

Beta glucan

Several natural polysaccharides have been reported to have gastrointestinal protective effects (Ding et al., 2017; Oliveira et al., 2018; Wang et al., 2018). Beta glucan is a heterogenous polysaccharide that, as a dietary fiber, has the tendency to maintain blood glucose and cholesterol levels and produce short chain fatty acids to promote the growth of beneficial microflora (Guo et al., 2018; Xu et al., 2013). In rats, treatment with soluble dietary fiber protects the GI mucosa against NSAIDs (Satoh and Urushidani, 2016). In 2019, Chen and colleagues revealed that beta glucan exerted protective effects on the gastric mucosa by alleviating neutrophil infiltration and lipid peroxidation through an antioxidant mechanism. Additionally, rats pretreated with beta glucan experienced a reduced inflammatory effect after ethanol-induced gastric ulcers, indicating the effective 
inhibition of pro-inflammatory cytokines. These results elucidate the antioxidant activity and anti-inflammatory potential of beta glucan (Chen et al., 2019).

\section{Hericium erinaceus}

In a study with rats, when comparing mucosal injury of ethanol-induced ulceration, there are similar effects of pre-treatment omeprazole and H. erinaceus extract. Ulcer area significantly decreased, and mucus production increased in a dose-dependent manner in rats given varying levels of $H$. erinaceus extract. Rats under pre-treatment with H. erinaceus extract showed near-normal histopathological architecture of gastric mucosa comparable to normal rats, whereas those pre-treated with omeprazole presented with mild inflammation and infiltration of leukocytes in the stomach. Additionally, elevated production of reactive oxygen species (ROS) was indicated by decreased superoxide dismutase (SOD) levels, causing gastric damage to those in the control group. Higher doses of H. erinaceus extract caused a significant increase in SOD activity as well as prevented a depletion in catalase (CAT) activities (Chen et al., 2019).

Administration of $H$. erinaceus extract has protective effects on gastric mucosa and inhibits infiltration of leukocytes into the gastric wall in ethanol-induced gastric ulcers. A reduction in neutrophil infiltration has been a proven marker of ulcer healing (Shimizu et al., 2000). Leukocytes, specifically neutrophils, act as inflammatory mediators that can release ROS that are highly cytotoxic and induce tissue damage (Cheng and Koo, 2000). Thus, suppression of infiltration during inflammation might hasten the rate of ulcer healing. 
The mucosal barrier plays a vital role in the protection of the gastric wall (Allen and Flemstrom, 2005). Free mucus was significantly increased in rats pre-treated with $H$. erinaceus extract in comparison with those in the ulcer control group. The mucus that adheres to the gastric wall protects the underlying epithelium from acid, pepsin and necrotizing agents (Alqasoumi et al., 2008).

\section{Hyaluronan}

In 2011, Al-Bayaty and colleagues performed a study to evaluate the antiulcerogenic activity of hyaluronic acid (HLA) against ethanol-induced gastric mucosal injury in rats (Al-Bayaty et al., 2009). Many tissues' extracellular matrix is largely composed of HLA, a large non-sulfated glycosaminoglycan which is made up of repeating disaccharides of D-glucuronic and N-acetyl-glucosamine (Toole, n.d.). Fibroblasts are the primary secretors of HLA into the extracellular matrix (Mesa et al., n.d.). High molecular weight HLA is physiologically macro-aggregating and can perform action against hyaluronidase, an enzyme that breaks down proteoglycans (PG) in connective tissues and is effective at reconstructing when applied topically to damaged barriers. In a non-disease state, PG in the mucosal connective tissue act as a barrier against bacterial invasion and the spread of bacterial toxins.

\section{Biochemical Analytes}

Adenosine deaminase

Adenosine deaminase (ADA) is an critical enzyme involved in purine metabolism that functions as a catalyst, allosteric modulator, and cell-cell communication molecule (Moreno et al., 2018). There are several activities of ADA that make it a potential 
therapeutic target for disease including catalytic activity, strict control of its concentration and its disruption of extracellular adenosine triphosphate (ATP) (Liu and Xia, 2015; Park and Gupta, 2013).

Extracellular purines (adenosine, ATP and ADP) and pyrimidines (UDP and UTP) are important signaling molecules that facilitate various biological processes such as the immune response and inflammation through purine receptors (Ralevic and Burnstock, 1998). Adenosine specifically functions as a signal to indicate tissue damage and inflammatory changes, and can act as a stress signal by autocrine or paracrine interactions (Camici et al., 2018; Kumar and Sharma, 2009). Adenosine can have different effects depending on target tissue, time course (Fredholm, 2007; Linden and Eltzschig, 2007) and receptor type, as various receptors have opposing functions (Fredholm, 2007; Linden and Eltzschig, 2007). Adenosine deaminase acts as an immunomodulatory and allosteric regulator by binding to adenosine receptors, and due to opposing functions of these receptors, can elicit pro- or anti-inflammatory effects, depending on immune status. An upregulation of ADA activity has been shown to result in inflammation and tissue injury, while a decrease in ADA activity has been associated with disease progression (da Silva et al., 2017; Saracoglu et al., 2005).

\section{Total antioxidant capacity}

Oxidative stress is a key element of tissue injury in gastric disease, and intestinal insult has been directly linked to increased free radical production and a low concentration of endogenous defense mechanisms (Grisham, 1994; Kruidenier and Verspaget, 2002). In a study with inflammatory bowel disease patients, TAC was 
significantly reduced and was independent of disease activity and localization (Koutroubakis et al., 2004). It is suggested that there is a relationship between serum TAC and mucosal antioxidant activity, measuring the totality of circulating antioxidants (Kampa et al., 2002; Malliaraki et al., 2003). Thus, it is a more accurate representation of chronic conditions instead of acute situations. A measured decrease in TAC may be attributable to several factors, including malabsorption and increased GI losses. A reduction in antioxidant defense may result in the compromise of inflamed mucosa, elevating its vulnerability to oxidative tissue damage (Koutroubakis et al., 2004). 


\section{CHAPTER TWO \\ EQUINE GASTRIC ULCERS: POLYSACCHARIDE SUPPLEMENTTION AS A SOLUTION}

\section{Introduction}

The term "Equine Gastric Ulcer Syndrome” (EGUS) encompasses several disorders of the stomach and can be further defined by location. Distinguishing between Equine Squamous Gastric Disease (ESGD) and Equine Glandular Gastric Disease (EGGD) is imperative, as their pathophysiology and treatment needs vary. Hydrochloric acid $(\mathrm{HCl})$ exposure, volatile fatty acid (VFA) injury, and the synergistic effect of bile acid and bacterial fermentation byproduct of non-structural carbohydrates (NSC) with $\mathrm{HCl}$ are major offenders of the squamous (SQ) mucosa. Successful injury resolution of SQ mucosa is widely achieved by the suppression of gastric acid. Pathophysiology of glandular (GL) mucosa is less well understood, but it is potential that nonsteroidal inflammatory drugs (NSAIDs) and bacteria play a role in the development of ulcers in this region. It has been found that GL ulcers require longer treatment duration than SQ ulcers, thus acid suppression coupled with therapies such as antimicrobials and mucosal coating agents show promise for efficient healing of the GL mucosa.

Omeprazole, a proton pump inhibitor (PPI), is the most common acid suppression therapy administered to horses suffering from ESGD and EGGD. It results in varying healing rates of the SQ and GL mucosa, is costly, and is not viable for long-term administration. The use of nutraceuticals and natural, long-term supplements are becoming a more appealing opportunity to the industry. Several options with varying 
rates of efficacy are available including pectin-lecithin complexes, magnesium

hydroxide, and sea buckthorn berries to name a few. More conclusively, high molecular weight hyaluronan (HA) has been proven to protect gastric mucosa from injury (AlBayaty et al., 2009), and beta glucan supports enhanced gastroprotection and contains bioactive components with anti-ulcer activities (Wong et al., 2013). The goal of this research was to quantify the effect of a natural supplement containing HA and beta glucan, further referred to as "polysaccharide supplement" (PS), on SQ and GL ulcers in the equine stomach.

\section{Materials and Methods}

This research was approved by the Institutional Animal Care and Use Committee of Clemson University (AUP \#2020-013).

\section{Induction}

Gastric ulcers were induced in horses using a modified Murray method before onset of the 6-week supplemental period. Horses alternated four 12-hour periods of feed deprivation and normal feeding routine as well as two 24-hour feed deprivations leading up to the initial endoscopy (Day 0), for a total of 108 hours of feed deprivation. After ulcers were induced, horses underwent an initial pre-screening endoscopy (Day 0) to determine the extent of gastric ulcer presence in the SQ and GL regions of the stomach. These results were assessed, and scores of SQ and GL ulcerations were assigned. Prior to the other two examinations (Days 21 and 42), horses were fasted for 16 hours and water withheld for a minimum of three hours to ensure visibility during the procedure. 


\section{Endoscopy}

Endoscopic examinations were performed with a $3 \mathrm{~m}$ long equine gastroscope by the same board-certified veterinarian on days 0,21, and 42. Preparation for endoscopies included feed and water restrictions, as well as sedation. Once sedated, horses were secured in stocks prior to the beginning of the procedure. Before alterations to the gastric environment were made, stomach fluid samples from the proximal and distal regions were aspirated via $60 \mathrm{~mL}$ syringe through the biopsy channel. During the endoscopic procedure, the stomach was distended by the insufflation of air until the SQ and GL regions were visible, then gastric contents were rinsed from the stomach surface using distilled water flushed through the biopsy channel. At the conclusion of the procedure the stomach was desufflated, the endoscope was withdrawn, and horses were recovered from sedation.

\section{Ulcer grading}

During the endoscopic examination, images were captured and digitized with a portable personal computer. Images of irritation, thickening of the mucosa, ulcers, and other abnormalities were captured. Location of the ulcers indicated further whether the horses had ESGD or EGGD. Lesion scores, assigned blindly by the veterinarian, ranged from 0-4 for each of the ulcer types (Table 1; (Sykes and Jokisalo, 2014, p. 1). 
Table 1: Grading system for the squamous and glandular mucosa

\begin{tabular}{|c|c|c|}
\hline & Squamous mucosa & Glandular mucosa \\
\hline Grade 0 & $\begin{array}{l}\text { The epithelium is intact } \\
\text { and there is no appearance } \\
\text { of hyperkeratosis }\end{array}$ & $\begin{array}{l}\text { The epithelium is intact } \\
\text { and there is no evidence of } \\
\text { hyperemia }\end{array}$ \\
\hline Grade 1 & $\begin{array}{l}\text { The mucosa is intact but } \\
\text { there are areas of } \\
\text { hyperkeratosis }\end{array}$ & $\begin{array}{l}\text { The mucosa is intact but } \\
\text { there are areas of } \\
\text { hyperemia }\end{array}$ \\
\hline Grade 2 & $\begin{array}{l}\text { Small, single, or multifocal } \\
(<5) \text { superficial lesions }\end{array}$ & $\begin{array}{l}\text { Small, single, or multifocal } \\
(<5) \text { superficial lesions }\end{array}$ \\
\hline Grade 3 & $\begin{array}{l}\text { Large, single deep or } \\
\text { multiple }(\geq 5) \text { focal } \\
\text { superficial lesions }\end{array}$ & $\begin{array}{l}\text { Large, single deep or } \\
\text { multiple }(\geq 5) \text { focal } \\
\text { superficial lesions }\end{array}$ \\
\hline Grade 4 & $\begin{array}{l}\text { Extensive lesions with } \\
\text { areas of apparent deep } \\
\text { ulceration }\end{array}$ & $\begin{array}{l}\text { Extensive lesions with } \\
\text { areas of apparent deep } \\
\text { ulceration }\end{array}$ \\
\hline
\end{tabular}

Experimental design

Eight mature geldings (Quarter Horse, Thoroughbred) were match-paired according to ulcer grade following the pre-screening endoscopy (Day 0). Horses ranged from 10 to 20 years in age and 534 to $643 \mathrm{~kg}$ in body weight (BW) and were randomly assigned to one of two groups; treatment (TRT; $n=4)$ or control $(C T R L ; n=4)$. The TRT horses received 1oz PS supplement top-dressed on their concentrate meals at 0600 and 1800hrs daily for 6 weeks. The experiment was divided into three periods: presupplementation (D 0), mid-supplementation (D 28), and post-supplementation (D 42). During each period, endoscopies were performed and stomach fluid samples were collected.

Diet

All horses were fed to meet or exceed the NRC suggested nutrient requirements for horses at maintenance (NRC, 2007). Daily diets consisted of fescue hay (Festuca 
pratensis) fed at a rate of $1.0 \% \mathrm{BW}$ (as-fed) and a commercial concentrate (Nutrena ${ }^{\circledR}$ Triumph ${ }^{\circledR}$ Fiber Plus, Cargill ${ }^{\circledR}$, Inc., Holmesville, OH) fed at a rate of $0.25 \%$ BW (asfed). Daily diets were separated into two meals fed at 0600 and 1800 . Polysaccharide treatment (1oz) was fed to TRT horses at each meal. Composition of the supplement included purified water, liquid Aspergillus oryzae fermentation product, H. erinaceus (lion's mane) extract, hyaluronan, sodium chloride, xanthan gum, citric acid, potassium sorbate and sodium benzoate (BioZyme ${ }^{\circledR}$, Inc., St. Joseph, MO). There were no refusals of diet or treatment. Two 0.809 ha pastures (PAS; $\mathrm{n}=4$ horses per pasture) composed of fescue (Fescue pratensis), clover (Trifolium repens), annual rye (Lolium multiflorum) and other native grasses were utilized. Water was provided ad libitum.

\section{Management of horses}

All horses were weighed weekly with feed amounts adjusted accordingly. Horses were housed in $3.05 \times 3.65 \mathrm{~m}$ stalls and turned out into PAS from $0600-1800 \mathrm{hrs}$ and $1800-$ 0600hrs, respectively.

After conclusion of the 6-week supplementation period, horses with remaining ulcerations upon final endoscopy (D 42) underwent oral omeprazole treatment based on severity. Those with scores $0-1$ in the SQ and/or GL region were exempt from treatment. Those with scores of 2 or higher in the SQ region, GL region or both received a full dose of Gastrogard ${ }^{\circledR}$ once daily on an empty stomach for 2 weeks. This was followed by a half dose or a 500lb dose, once daily for 2 weeks. Finally, the horses underwent a $2501 \mathrm{~b}$ dose once daily for 2 weeks. Horses that underwent Gastrogard ${ }^{\circledR}$ treatment were subject to an additional endoscopy after 2 weeks of treatment in order to assess efficacy (D 76). 


\section{Statistical analyses}

The effects of date and treatment were analyzed with a factorial ANOVA. All statistical calculations were performed using the software JMP.

\section{Results}

Ulcer scores

There was no difference between mean ulcer scores of TRT and CTRL groups across time (Figure 2.1; $\mathrm{P}=0.776$ ). However, over the course of the 6-week supplemental period, all horses' pooled SQ and GL ulcer scores decreased (Figure 2.2; $\mathrm{P}=0.001$ ). While the overall main effect of ulcer scores between SQ and GL regions did not differ, at day 42 it was noted that SQ tissue presented with higher ulcer scores than GL (Figure 2.3; $\mathrm{P}=0.006$ ). Further, between TRT and CTRL horses, no difference was seen between SQ and GL ulcer scores across time (2.4a-b; $\mathrm{P}=0.145,0.859$ and 0.437 for day 0,21 and 42 , respectively. 
Figure 2.1: Gastric ulcer scores on day 0, 21 and 42 of polysaccharide supplemented (TRT; $n=4)$ versus non-supplemented horses (CTRL; $n=4$ )

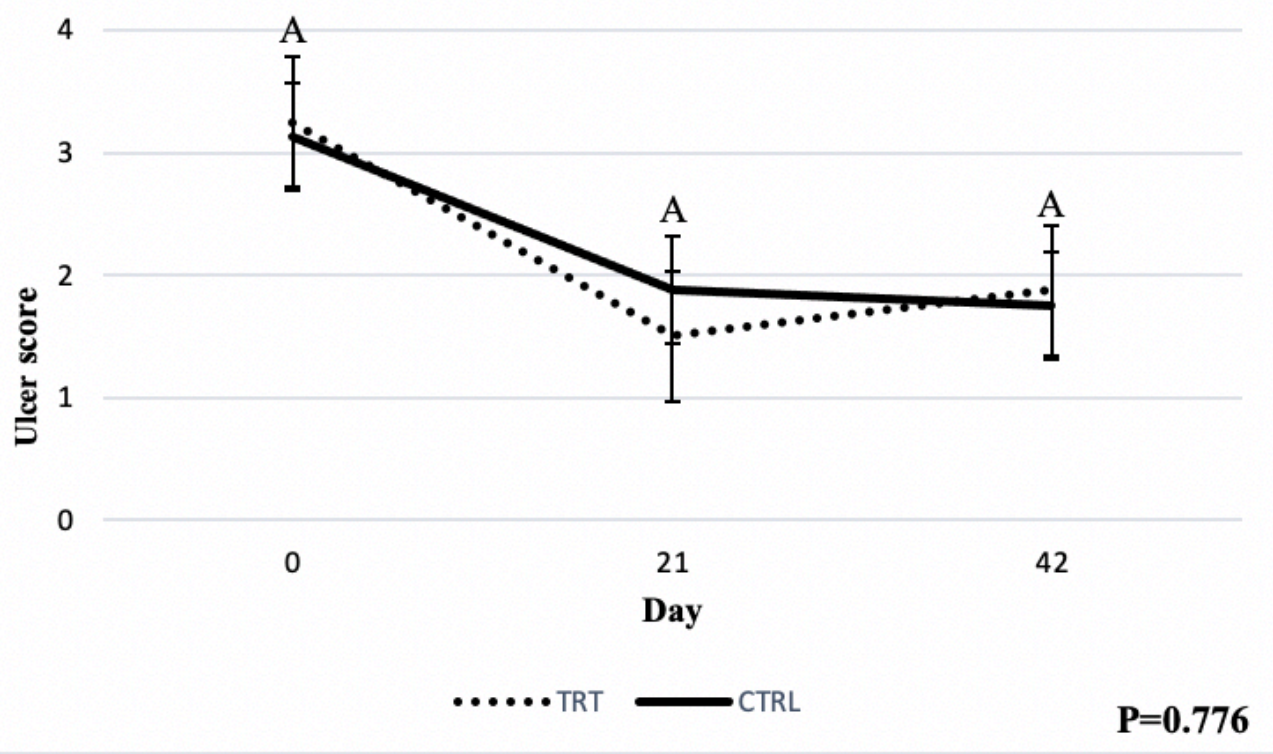

A Days with different letters are significantly different

Figure 2.2: Gastric ulcer scores on day 0,21 and 42 of all experimental horses $(n=8)$

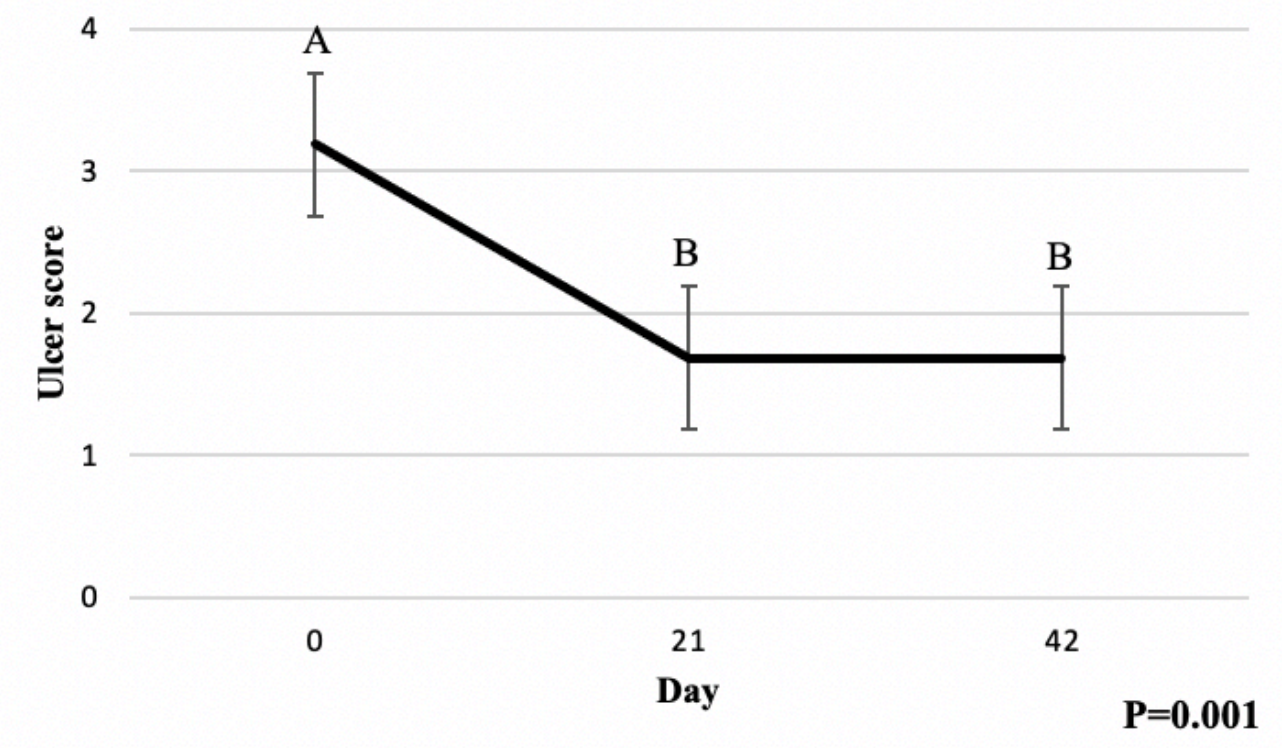

AB Days with different letters are significantly different 
Figure 2.3: Squamous (SQ) versus glandular (GL) gastric ulcer scores on day 0, 21 and 42 of all experimental horses $(n=8)$

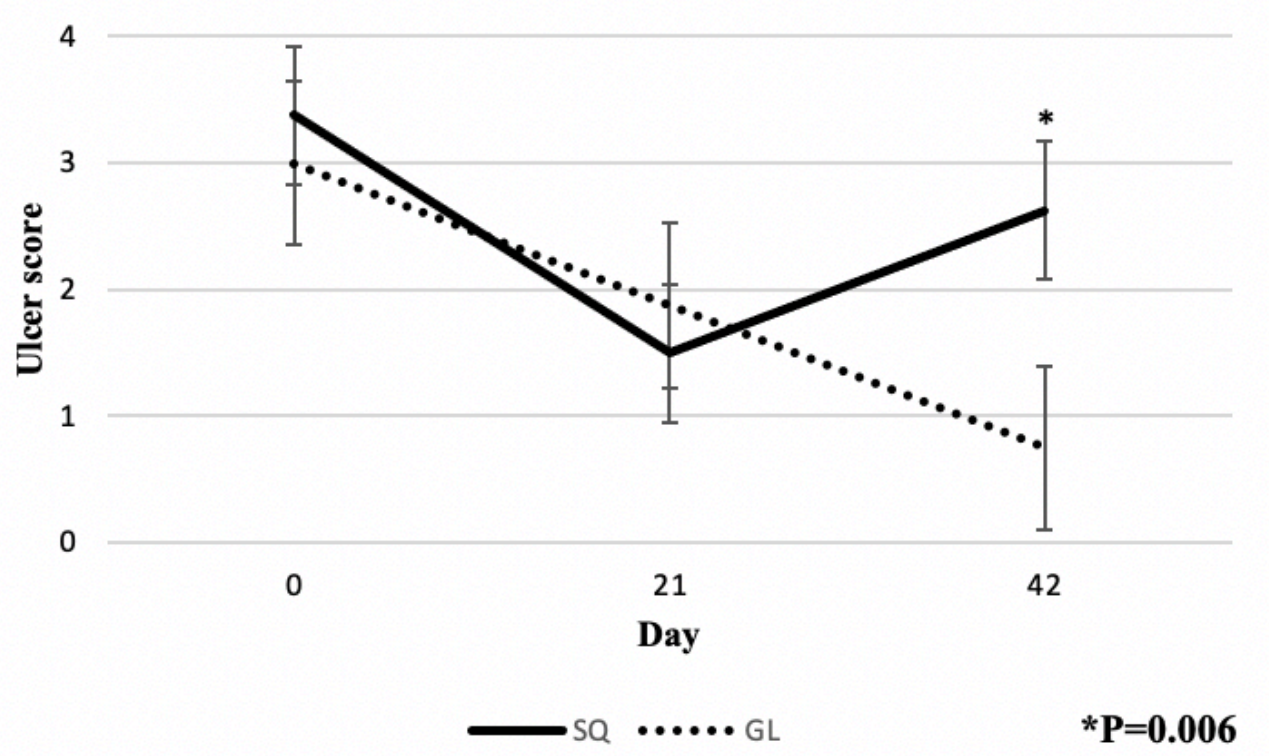

*Indicates significant differences in squamous tissue ulcer scores compared to glandular tissue ulcer scores on a specific day

Figure 2.4a: Squamous (SQ) gastric ulcer scores on day 0, 21 and 42 of polysaccharide supplemented horses (TRT; $n=4)$ versus non-supplemented horses (CTRL; $n=4)$

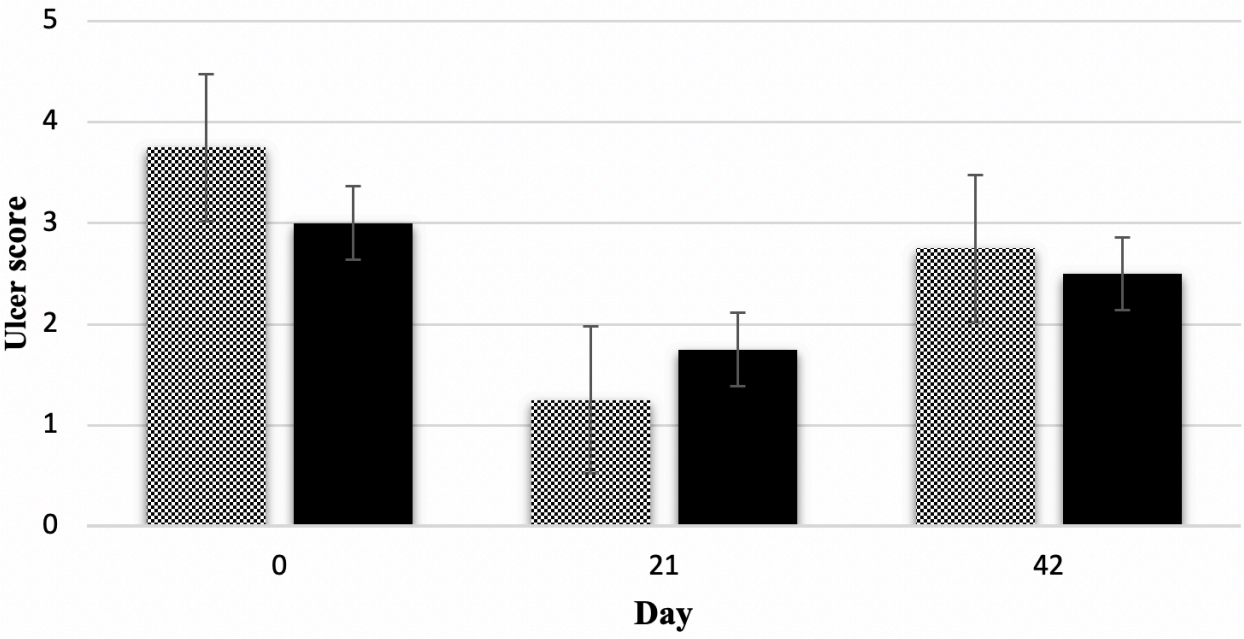

:SQ TRT $\square S Q C T R L$

Main effect $\mathrm{P}>0.05$ 
Figure 2.4b: Glandular (GL) gastric ulcer scores on day 0, 21 and 42 of polysaccharide supplemented horses (TRT; $n=4$ ) versus non-supplemented horses (CTRL; $n=4$ )

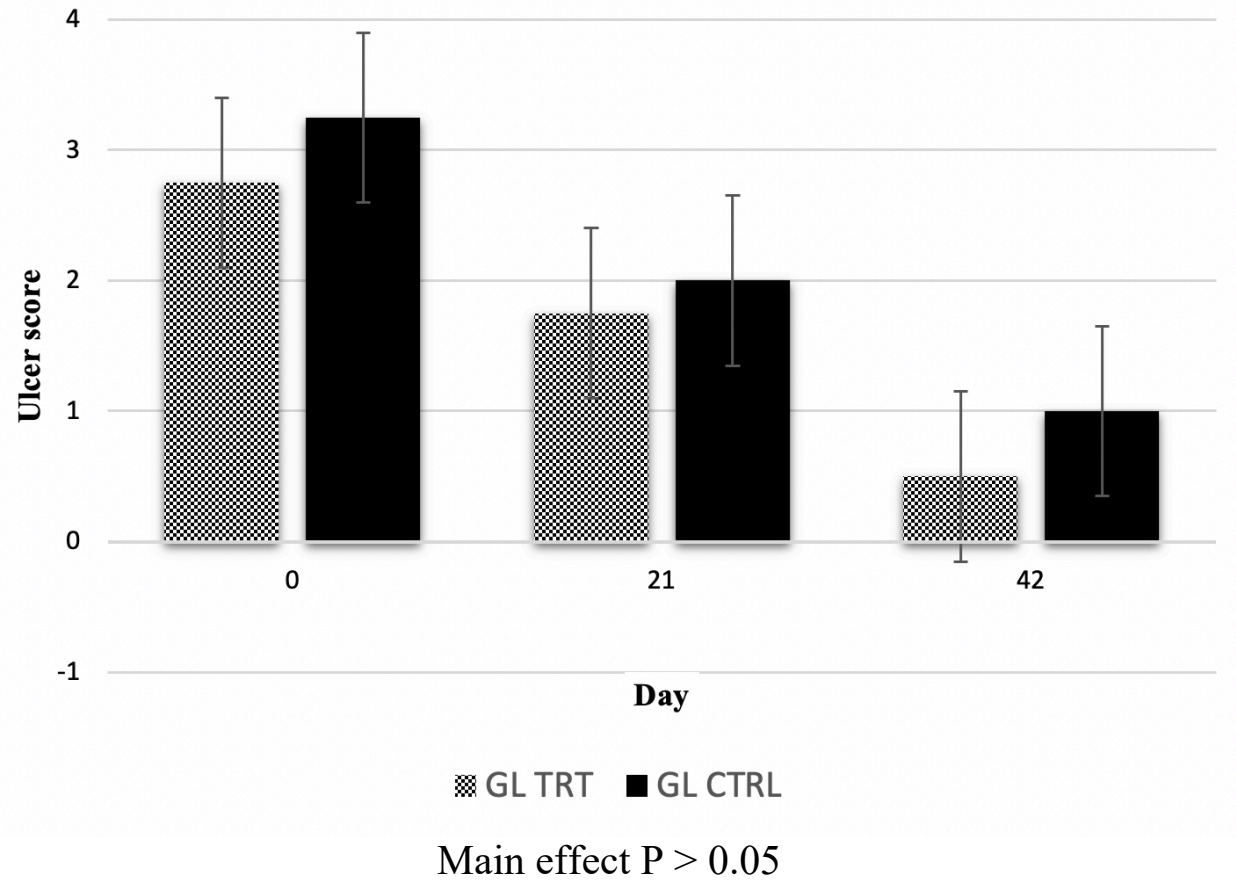

Further statistical analyses were completed with the inclusion of a block for ulcer location (UL). In the SQ region, UL were defined as: $1=$ near the margo plicatus (MP) and $2=$ other than near the MP. In the GL region, UL were defined as: $3=$ in the pyloric (P) region and $4=$ other than in the $\mathrm{P}$ region. A difference was seen among all UL for both TRT and CTRL groups across time (Figure 2.5; $\mathrm{P}=0.0463$ ). Despite these time differences, there was no overall difference between the SQ and GL regions of the TRT and CTRL groups $(\mathrm{P}=0.5448)$. 
Figure 2.5: Ulcer scores in various areas (margo plicatus (MP), non-margo plicatus (NMP), pylorus (P) and non-pylorus (NP)) on day 0, 21 and 42 of all experimental horses $(\mathrm{n}=8)$

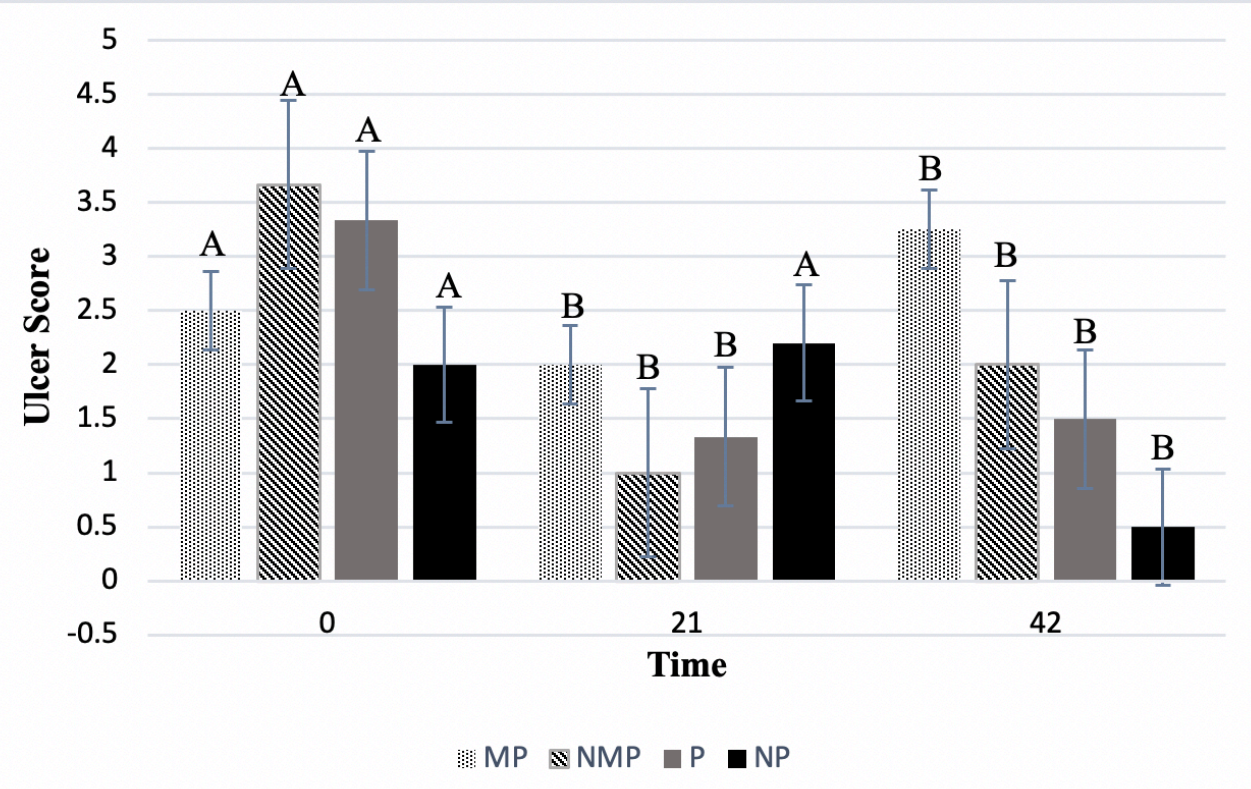

AB Ulcer location across days 0,21 and 42 with different letters differ statistically $(\mathrm{P}<$ $0.05)$

Main effect $\mathrm{P}<0.01$

\section{Gastric $p H$}

There was no difference in proximal or distal $\mathrm{pH}$ between TRT and CTRL groups across time $(\mathrm{P}=0.487)$. As expected, there was a difference between the $\mathrm{pH}$ values in the proximal and distal portions of the stomach across all horses (Figure 2.6; $\mathrm{P}=0.014$ ). 
Figure 2.6: $\mathrm{pH}$ values of the proximal and distal regions of the equine stomach on day 0 , 21 and 42 of all experimental horses $(n=8)$

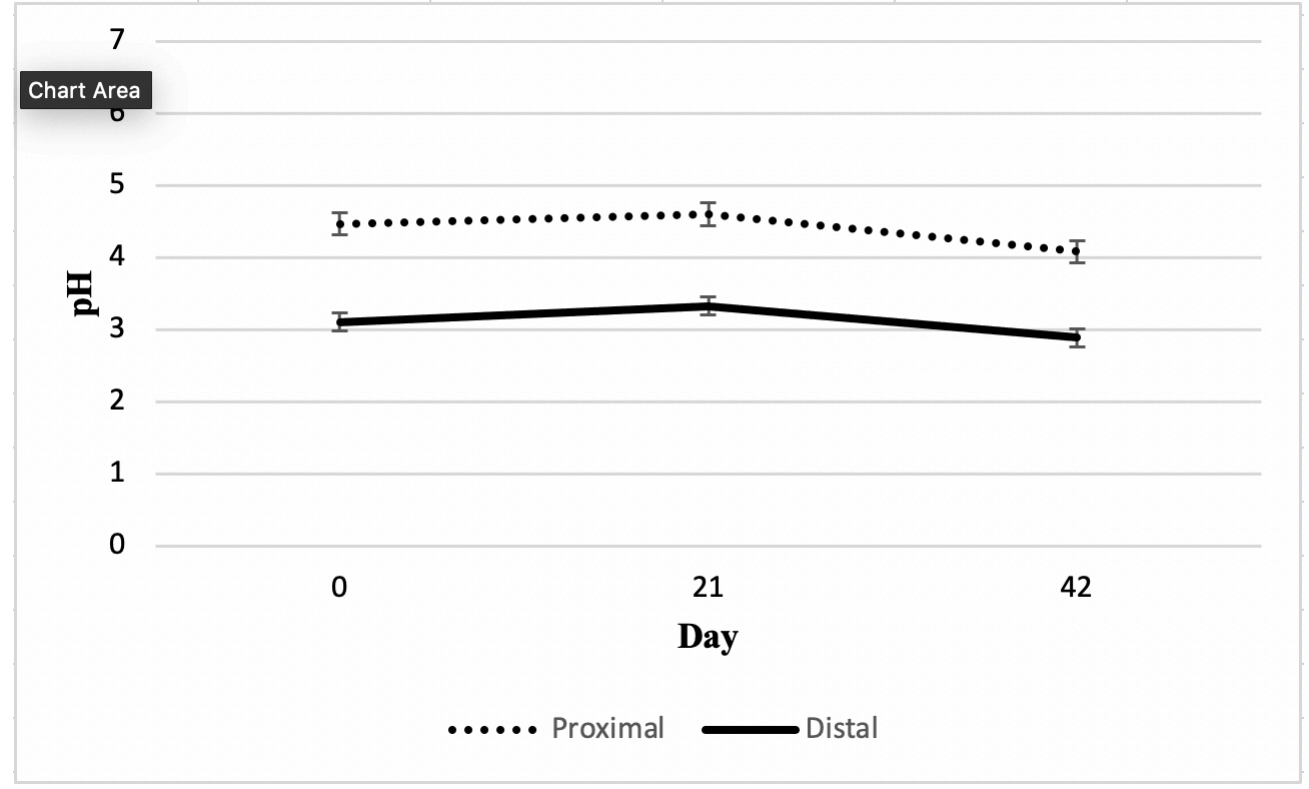

Main effect $\mathrm{P}=0.0143$

\section{Discussion}

The severity of ulcer scores in all experimental horses indicated that the modified Murray induction method was adequate to test the hypothesis and to induce lesions to the gastric mucosa. While there was no difference between mean ulcer scores of TRT and CTRL groups, there was an overall decrease in the horses' pooled SQ and GL ulcer scores over the course of the 6-week supplemental period. This lack of difference may be attributable to the horses' inactivity, as it has been shown that there is a strong relationship between exercise intensity and duration with prevalence, severity and number of lesion sites (Murray et al., 1996; Roy et al., 2005; Orsini et al., 2009). Moreover, the supplementation of polysaccharide therapy may have shown a lack of effect due to the provoked condition of the gastric mucosa and may instead be effective 
in maintaining mucosa of horses with naturally occurring ulcers. In another study concerning the effect of polysaccharides on equine gastric ulcers, supplementation was found to resolve or improve $90 \%$ of ulcerations in adult horses in active training (Slovis, 2017). Additionally, adeptness of the mucosa to naturally heal should be considered, as CTRL horses had an improvement of $44 \%$ overall ulcer score, $17 \%$ SQ score, and $70 \%$ GL score over the 6-week supplemental period. There are several factors that may have aided in the natural healing process, the first being constant access to forage in the form of hay or pasture. In 2015, Sykes and colleagues highlighted the reduced risk of ulceration alongside free access or frequent feeding of fibrous roughage. Further, horses were fed minimal percentage of their BW in concentrates, thus non-structural carbohydrates, as recommended by the NRC. Since it has been shown that starch intake increases the likelihood of gastric ulceration, it is possible that the minimal offering of concentrates further contributed to the high natural healing rates (Luthersson et al., 2009b).

No difference was found between the SQ and GL ulcer scores of all horses until day 42, where SQ ulcer scores were markedly higher than GL ulcer scores. This aligns with recent literature which found there is no relationship between ESGD and EGGD in the sense that one cannot be used as a predictor for the presence or absence of the other (Sykes et al., 2015a). Additionally, there was no difference of SQ and GL ulcer scores between TRT and CTRL groups. Given the differences in pathogenesis, prevalence and risk factors, it might be that after sufficient time, supplementation could potentially affect the SQ and GL mucosa differently. Differing treatment recommendations for SQ and GL 
ulcers is a novel concept. Investigation on this subject is warranted as remarkable differences in healing rates have been recorded between SQ and GL ulcers with omeprazole treatment regarding duration of acid suppression, duration of treatment, and use of adjunctive therapies (Sykes et al., 2015a). Typically, GL ulcers require longer treatment duration than SQ ulcers, and treatment methods are targeted towards resolving the breakdown of natural barriers as opposed to reducing exposure to acidic injury. The SQ tissue can benefit from limiting contact of acidic gastric contents in order for intercellular tight junctions and intracellular buffering systems to regain function, and GL tissue has an opportunity to heal when coating agents form a pseudomucus layer, allowing for the tissue to regenerate the integrity of the mucosal layer. Pharmaceuticals and nutraceuticals can collaborate to create the most conducive environment for gastric healing. While acid suppression is currently the cornerstone for treatment of both SQ and GL tissues, the role of the efficacy of adding adjunctive therapies should not be dismissed.

Within the SQ and GL mucosa, there are areas that appear to be more prone to irritation and ulceration. The area surrounding the margo plicatus (MP) is a common lesion site in the SQ portion of the stomach, while the pyloric region $(\mathrm{P})$ is where GL lesions are most commonly found. In the current study, of the SQ ulcerations observed, $61 \%$ were present around the MP while $65 \%$ of GL ulcerations were in the P region. A difference was seen among ulcer locations (UL) for both TRT and CTRL groups across time. As of late, histopathological findings are being used in an attempt to differentiate pathogeneses of disease of various regions of the equine stomach. The SQ tissue reacts to 
excessive exposure to acidic gastric contents by thickening and becoming hyperkeratotic, which eventually results in the sloughing of the superficial layers of the mucosa. This leads to vulnerability of the mucosa to opportunistic bacteria, followed by the localized migration of inflammatory cells. The lesion will deepen, allowing for progression to ulceration, which fully exposes the tissue to acidic contents of the stomach (Martineau et al., 2009). This sequence of events occurs most commonly at the MP because it is the most vulnerable region of SQ tissue due to anatomical configuration of the equine stomach and its role as the intersection between the two tissue types. Thus, it is more prone to exposure to acidic gastric contents and does not possess the protective properties present in the GL mucosa. The process of spontaneous GL tissue ulceration is less understood. Excessive acid exposure does not seem to be a primary factor and studies speculating the harboring of an equine specific Helicobacter-like organism have yielded inconsistent results (Blikslager et al., 2017). Mucosal injury via refluxed bile acids should be considered, as this is a common occurrence in horses and can result in irritation to the mucosa. Interestingly, adaptive protection of the GL mucosa from the irritating effects of bile acids has been previously described, as injury typically occurs only when mucosal protective processes are impaired (Murray et al., 2001).

Though there were no differences of $\mathrm{pH}$ between the TRT and CTRL groups, there was a difference between the proximal and distal regions' $\mathrm{pH}$ levels across all horses. Consistently, it was found that distal $\mathrm{pH}$ was lower than proximal $\mathrm{pH}$. Literature supports that the $\mathrm{pH}$ in the distal region of the stomach is relatively stable around 3 , which aligns with findings of the current study (Sykes and Jokisalo, 2015, p. 3). Proximal 
$\mathrm{pH}$ did not drop below 4, so the presence of ulcers is contradictory to literature defining this threshold as ulcerogenic for SQ tissue (Husted et al., 2009). This difference may be due to the lack of an induction in horses in the aforementioned study.

\section{Conclusion}

Polysaccharide supplementation at $10 z$ twice per day over a 6-week period did not have an effect on ulcer scores in the SQ or GL region. A significant recovery was seen by all experimental horses following the induction of gastric ulcers. The endoscopy on day 42 revealed elevated SQ ulcer scores, supporting that healing rates of SQ and GL tissue are independent of each other. Additionally, the polysaccharide supplement did not influence $\mathrm{pH}$ values and all horses exhibited higher proximal than distal $\mathrm{pH}$. The lack of effect may be due to conditions of induced ulcers, as studies involving naturally occurring ulcers have shown a more positive healing effect from polysaccharide supplementation. It may be beneficial to evaluate the efficacy of polysaccharide supplementation in horses that are active in training with naturally occurring ulcers. 


\section{CHAPTER THREE}

\section{EQUINE GASTRIC ULCERS: ASSOCIATED BIOMARKERS}

\section{Introduction}

The prevalence of EGUS varies with breed, use, level of training, as well as between ESGD and EGGD (Sykes and Jokisalo, 2015). Up to 90\% of performance horses are affected by gastric ulcers. Individual cases vary with clinical signs including reduced appetite, poor body condition, behavioral inconsistencies, and reduced performance, among others. There are many risk factors, with exercise and diet being the most influential. Currently, the only reliable antemortem diagnostic method for EGUS is endoscopy. This procedure involves feed and water restriction, as well as sedation.

Though it is definitive, the process of endoscopy is cost-prohibitive and is not accommodating to the equine stomach. As fasting is a risk factor for the development of ulcers, it seems counterintuitive to require it for diagnosis. The development of a salivary or serum panel for aid in the diagnostics of EGUS would provide a much less expensive and invasive method of determining gastric integrity.

Saliva, which is composed of $99 \%$ water, contains other compounds, hormones, and enzymes that have potential for aiding in diagnostics of systemic disorders. Saliva poses some advantages over blood collection, as it is non-invasive, non-stressful, and can be performed by those without training. Salivary analytes have been assessed in several species, including swine and equine, and usually revolve around markers indicative of stress response. There are minimal studies evaluating panels of analytes associated with Equine Gastric Ulcer Syndrome (EGUS). An exploratory study followed up with a 
confirmatory study in 2019 found several analytes that were elevated in horses with acute abdominal disease and also correlated with their respective serum concentrations (Contreras-Aguilar et al., 2019).

Though it is more invasive than saliva collection, blood collection for serum analysis is markedly less invasive and expensive than an endoscopic procedure, and the process can be taught with minimal training. Various biochemical markers are useful for measuring values such as oxidative stress, pathologic conditions, and immune response (Bagheri et al., 2019; Beyazit et al., 2012).

The goal of this research was to establish a relationship between salivary and serum analytes with gastric ulcer scores of the SQ and GL region of the equine stomach in order to potentiate a less-invasive diagnostic technique for EGUS.

\section{Materials and Methods}

This research was approved by the Institutional Animal Care and Use Committee of Clemson University (AUP \#2020-013). Experimental design

Eight mature geldings (Quarter Horse, Thoroughbred) were match-paired according to ulcer grade following the pre-screening endoscopy (Day 0). Horses ranged from 10 to 20 years in age and 534 to $643 \mathrm{~kg}$ in body weight (BW) and were randomly assigned to one of two groups; treatment (TRT; $n=4)$ or control (CTRL; $n=4)$. The TRT horses received 1oz PS supplement top-dressed on their concentrate meals at 0600 and 1800hrs daily for 6 weeks. The experiment was divided into three periods: presupplementation (D 0), mid-supplementation (D 28), and post-supplementation (D 42). 
During each period, endoscopies were performed and stomach fluid samples were collected.

Diet

All horses were fed to meet or exceed the NRC suggested nutrient requirements for horses at maintenance (NRC, 2007). Daily diets consisted of fescue hay (Festuca pratensis) fed at a rate of $1.0 \% \mathrm{BW}$ (as-fed) and a commercial concentrate (Nutrena ${ }^{\circledR}$ Triumph $^{\circledR}$ Fiber Plus, Cargill ${ }^{\circledR}$, Inc., Holmesville, OH) fed at a rate of $0.25 \%$ BW (asfed). Daily diets were separated into two meals fed at 0600 and 1800 . Polysaccharide treatment (1oz) was fed to TRT horses at each meal. Composition of the supplement included purified water, liquid Aspergillus oryzae fermentation product, H. erinaceus (lion's mane) extract, hyaluronan, sodium chloride, xanthan gum, citric acid, potassium sorbate and sodium benzoate (BioZyme ${ }^{\circledR}$, Inc., St. Joseph, MO). There were no refusals of diet or treatment. Two 0.809 ha pastures (PAS; $\mathrm{n}=4$ horses per pasture) composed of fescue (Fescue pratensis), clover (Trifolium repens), annual rye (Lolium multiflorum) and other native grasses were utilized. Water was provided ad libitum.

\section{Management of horses}

All horses were weighed weekly with feed amounts adjusted accordingly. Horses were housed in $3.05 \times 3.65 \mathrm{~m}$ stalls and turned out into PAS from $0600-1800 \mathrm{hrs}$ and $1800-$ 0600hrs, respectively.

After conclusion of the 6-week supplementation period, horses with remaining ulcerations upon final endoscopy (D 42) underwent oral omeprazole treatment based on severity. Those with scores $0-1$ in the SQ and/or GL region were exempt from treatment. 
Those with scores of 2 or higher in the SQ region, GL region or both received a full dose of Gastrogard ${ }^{\circledR}$ once daily on an empty stomach for 2 weeks. This was followed by a half dose or a 500lb dose, once daily for 2 weeks. Finally, the horses underwent a $250 \mathrm{lb}$ dose once daily for 2 weeks. Horses that underwent Gastrogard ${ }^{\circledR}$ treatment were subject to an additional endoscopy after 2 weeks of treatment in order to assess efficacy (D 76). Biological sampling

During each period, samples of saliva and blood were collected prior to endoscopic procedure. Though horses were in a fasted state, the mouth was rinsed of any remaining feedstuffs as a precautionary measure to avoid contamination. Saliva collection was performed by insertion of a $6.0 \times 10^{-4} \mathrm{~m}^{2}$ compressed sponge (Arcliber ${ }^{\circledR}$ cellulose sponge) through the bars of each horse's mouth to be chewed until saturated with saliva. The procedure lasted approximately 90 seconds. Then, sponges were placed into salivette tubes after removal of the included cotton swab (Salivette Tubes, Fisher Scientific ${ }^{\circledR}$ ) and were stored in a cooler until transport to Clemson University within the same day to be centrifuged at 3200rpm for 15 minutes. Following this, all were aliquoted into appropriately labeled microcentrifuge tubes (Eppendorf ${ }^{\mathrm{TM}}$ Tubes, Fisher Scientific ${ }^{\circledR}$ ) and stored at $-80^{\circ} \mathrm{C}$.

Blood samples were collected by jugular venipuncture into Vacutainer ${ }^{\circledR}$ rapid serum test (RST) tubes via a double-ended bleeding needle (BD Vacutainer ${ }^{\circledR}$ Rapid Serum Tubes, Mississauga, ON). Blood samples were stored in a cooler until transport to Clemson University within the same day to be centrifuged at 1300rpm for 15 minutes. 
Following this, all were aliquoted into appropriately labeled microcentrifuge tubes (Eppendorf ${ }^{\mathrm{TM}}$ Tubes, Fisher Scientific ${ }^{\circledR}$ ) and stored at $-80^{\circ} \mathrm{C}$.

\section{Biochemical analyses}

Adenosine deaminase

The salivary and serum levels of ADA activity were quantified using an optimized adaptation of a commercial automatized assay (BioSystems S.A.; Gutiérrez et al., 2017). The method of the assay is based on the measurement of the decrease in absorbance (OD) per minute of a coupled reaction initially catalyzed by ADA. The reaction is measured at $340 \mathrm{~nm}$. The levels of ADA activity were calculated according to the manufacturer's instructions $(\Delta \mathrm{OD} / \mathrm{min} \times 3333=\mathrm{U} / \mathrm{L})$. The optimal sample dilutions were 1:8 for saliva and 1:4 for serum samples.

\section{Cortisol and alpha amylase}

The cortisol content in the salivary samples were measured using an optimized commercial competitive ELISA assay (Extended range high sensitivity salivary cortisol Enzyme immunoassay kit, Salimetrics, USA). No dilution of horse saliva was applied under the optimal conditions of the assay. Cortisol levels were calculated according to the manufacturer's instructions $(3 \mu \mathrm{g} / \mathrm{dL}=82.77 \mathrm{nmol} / \mathrm{L})$.

\section{Total antioxidant capacity}

The TAC was measured in the saliva and serum samples by the ferric reducing antioxidant power assay, which was optimized for the two-horse body-fluids (Benzi et al., 1996). The method consisted in the reduction of the ferric complex tripiridil triazine (Fe3+ TPTZ) to form Fe2+ in an acidic medium. Prior to its implementation, the optimal 
sample dilution was calculated using a standard curve of Trolox (a water-soluble analog of vitamin E employed as a control antioxidant agent for assay calibration), ranging from 1.5 to $100 \mu \mathrm{M}$ Trolox equivalents. No sample dilution was required.

\section{Total protein}

The total protein content of serum and saliva samples was determined according to standard protocols (Bradford, 1976). A calibration curve with five standards based on bovine serum albumin was used with a concentration range of 5-100 ng/mL. For serum determinations, a sample dilution of 1:1000 was used while for saliva the optimal dilution for analysis was 1:20.

Immunoglobulin levels

For the quantifications of serum IgG levels, serum samples were diluted at 1:200000 for proper measurements using a commercial ELISA assay (IgG Horse ELISA kit, Abnova) according to the manufacturer's instructions. The amount of salivary IgA was measured using an optimized commercial ELISA assay (IgA Horse ELISA kit, Abnova) with a saliva dilution of 1:5000.

\section{Results}

Biochemical analytes

Salivary analytes

There was no correlation between salivary total protein (TP), cortisol (CORT), and immunoglobulin A (IgA) concentrations and ulcer scores in the SQ or GL regions of the TRT or CTRL group. However, TRT horses' adenosine deaminase (ADA) concentrations had a tendency to correlate with ulcer scores in the GL region (Figure 3.1; 
$\left.\mathrm{P}=0.061 ; \mathrm{R}^{2}=0.308\right)$. In the CTRL group, there was a negative correlation between total antioxidant capacity (TAC) and GL ulcer scores (Figure 3.2; $\mathrm{P}=0.051 ; \mathrm{R}^{2}=0.330$ ).

Figure 3.1: Salivary adenosine deaminase (ADA) concentrations from day 0, 21 and 42 sample collections in polysaccharide supplemented (TRT; $n=4)$ and non-supplemented horses (CTRL; $\mathrm{n}=4$ ) with glandular (GL) ulcers

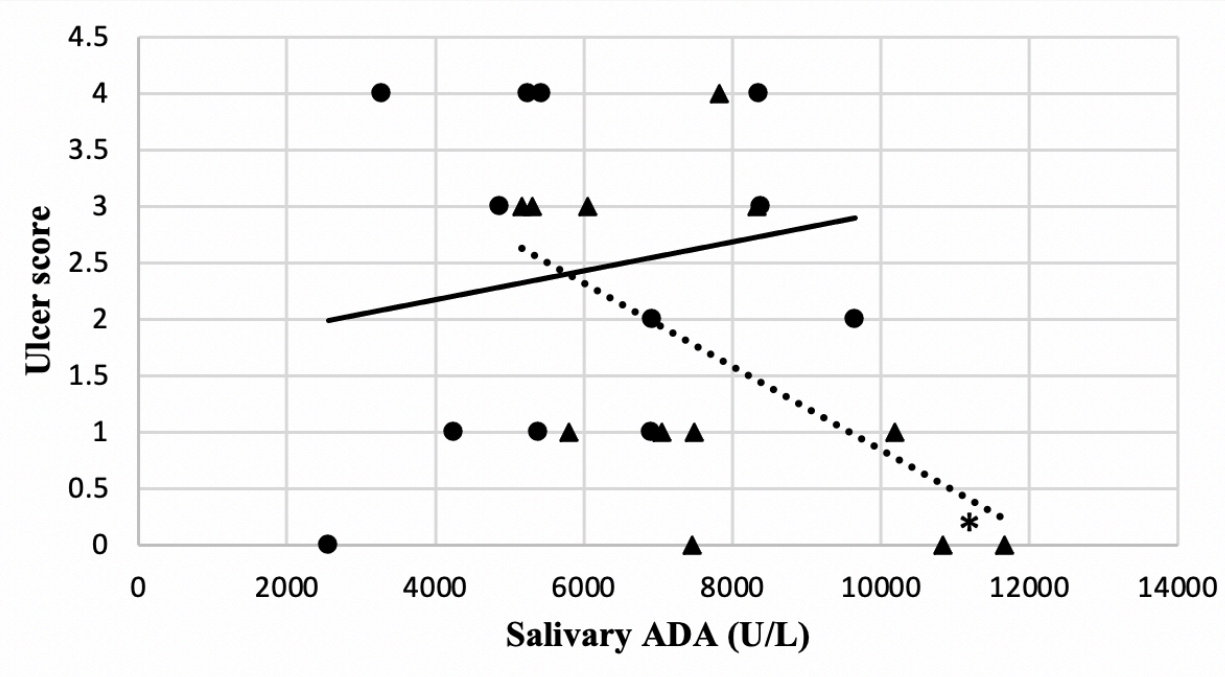

\ TRT GL $\quad$ C CTRL GL $\quad \cdots \cdots$... Linear (TRT GL) — Linear (CTRL GL)

*Indicates trend for linear significance $(\mathrm{P}=0.061)$

Linear $\mathrm{y}=-0.0004 \mathrm{x}+4.5387$

$$
\mathrm{R}^{2}=0.308
$$


Figure 3.2: Salivary total antioxidant capacity (TAC) concentrations in polysaccharide supplemented (TRT; n=4) and non-supplemented horses (CTRL; n=4) with glandular (GL) ulcers

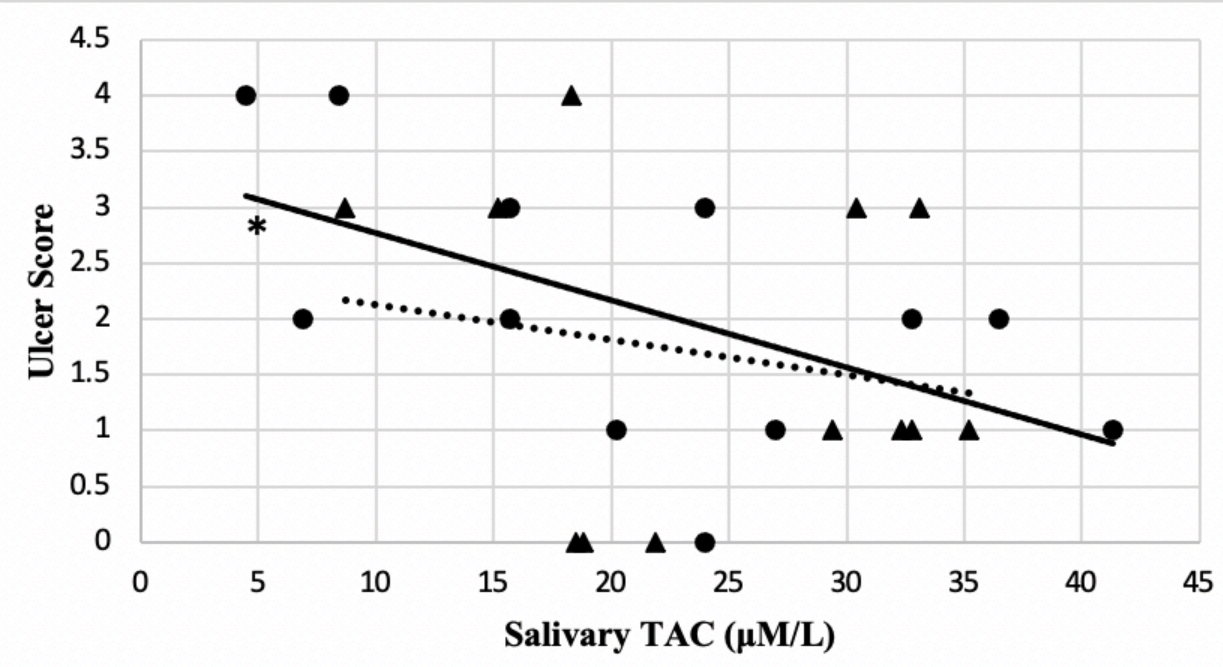

- CTRL GL $\quad \Delta \quad$ TRT GL $\quad$ Linear (CTRL GL) $\quad \cdots .$. Linear (TRT GL)

*Indicates significant linear trend $(\mathrm{P}=0.051)$

$$
\begin{gathered}
y=-0.0604 x+3.3768 \\
R^{2}=0.330
\end{gathered}
$$

\section{Serum analytes}

There was no correlation between serum ADA or TP concentrations with SQ

ulcer scores of the TRT or CTRL group, nor any correlation between serum TAC concentration in the TRT group. There was no correlation between serum ADA concentration in the CTRL group, TAC in both groups nor TP concentration in the TRT group with GL ulcer scores. However, there was a strong positive correlation found between serum TAC and SQ scores in the CTRL group (Figure 3.3; $\mathrm{P}=0.002 ; \mathrm{R}^{2}=0.620$ ). In the TRT group, a positive correlation was found for serum ADA and GL ulcer scores (Figure 3.4; $\mathrm{P}=0.028 ; \mathrm{R}^{2}=0.399$ ). In the $\mathrm{CTRL}$ group, a negative correlation was found between GL ulcer score and serum TP levels (Figure 3.5; $\mathrm{P}=0.016 ; \mathrm{R}^{2}=0.456$ ). 
Figure 3.3: Serum total antioxidant capacity (TAC) levels in polysaccharide supplemented (TRT; $n=4$ ) and non-supplemented horses (CTRL; n=4) with squamous (SQ) ulcers

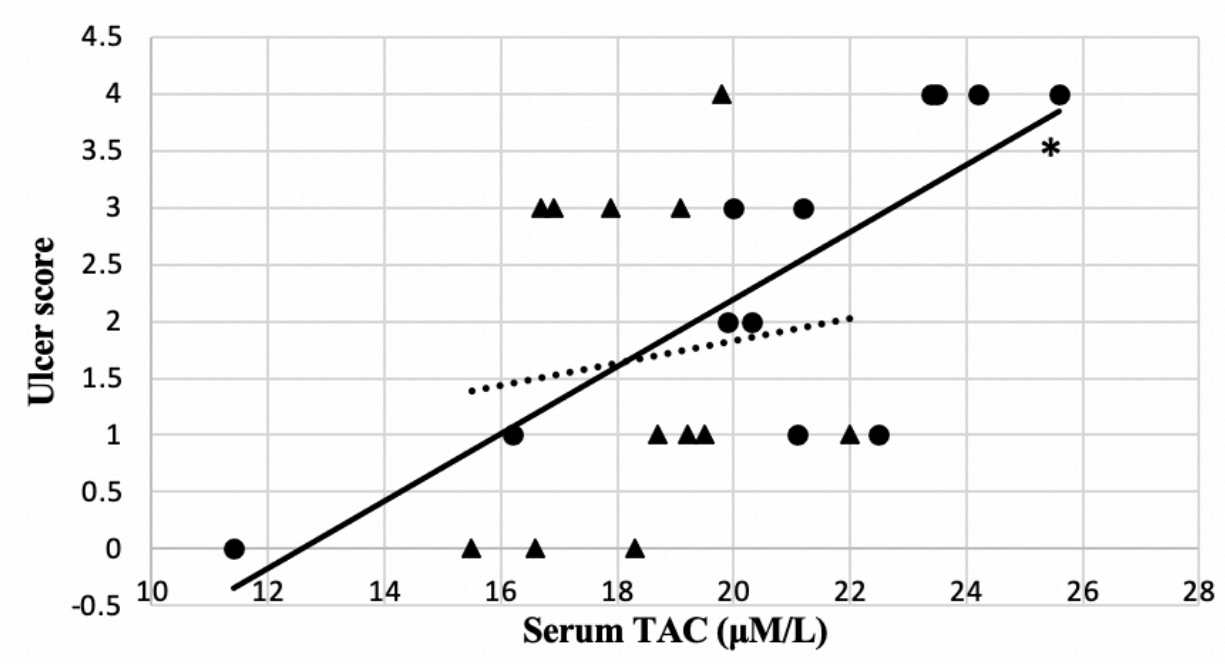

- CTRLSQ $\quad$ TRTSQ $\quad$ Linear (CTRL SQ) $\cdots . . . .$. Linear (TRT SQ)

*Indicates significant linear trend $(\mathrm{P}=0.002)$

$$
\begin{gathered}
y=0.2952 x-3.717 \\
R^{2}=0.62
\end{gathered}
$$

Figure 3.4: Serum adenosine deaminase (ADA) levels in polysaccharide supplemented (TRT; $\mathrm{n}=4)$ and non-supplemented horses (CTRL; $\mathrm{n}=4$ ) with glandular (GL) ulcers

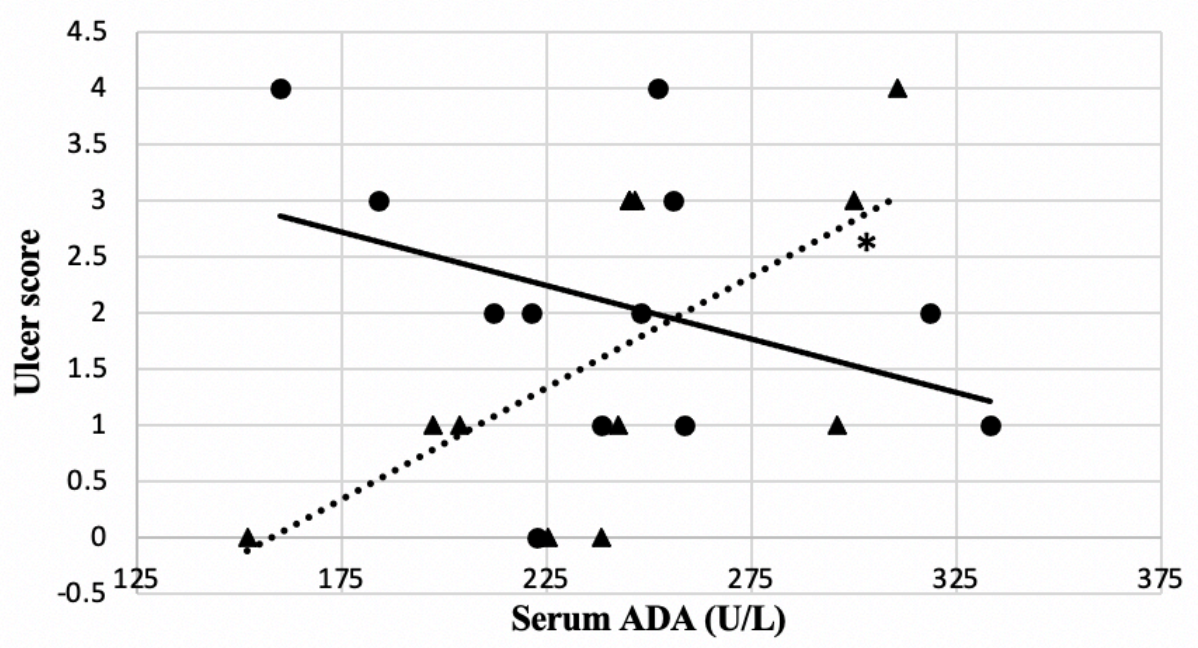

\ $\quad$ TRT GL

- CTRL GL

•..... Linear (TRT GL) Linear (CTRL GL)

*Indicates significant linear trend $(\mathrm{P}=0.028)$

$$
\begin{gathered}
\mathrm{y}=0.0199 \mathrm{x}-3.1444 \\
\mathrm{R}^{2}=0.3987
\end{gathered}
$$


Figure 3.5: Serum total protein (TP) levels in polysaccharide supplemented (TRT; $n=4$ ) and non-supplemented horses (CTRL; $\mathrm{n}=4$ ) with glandular (GL) ulcers

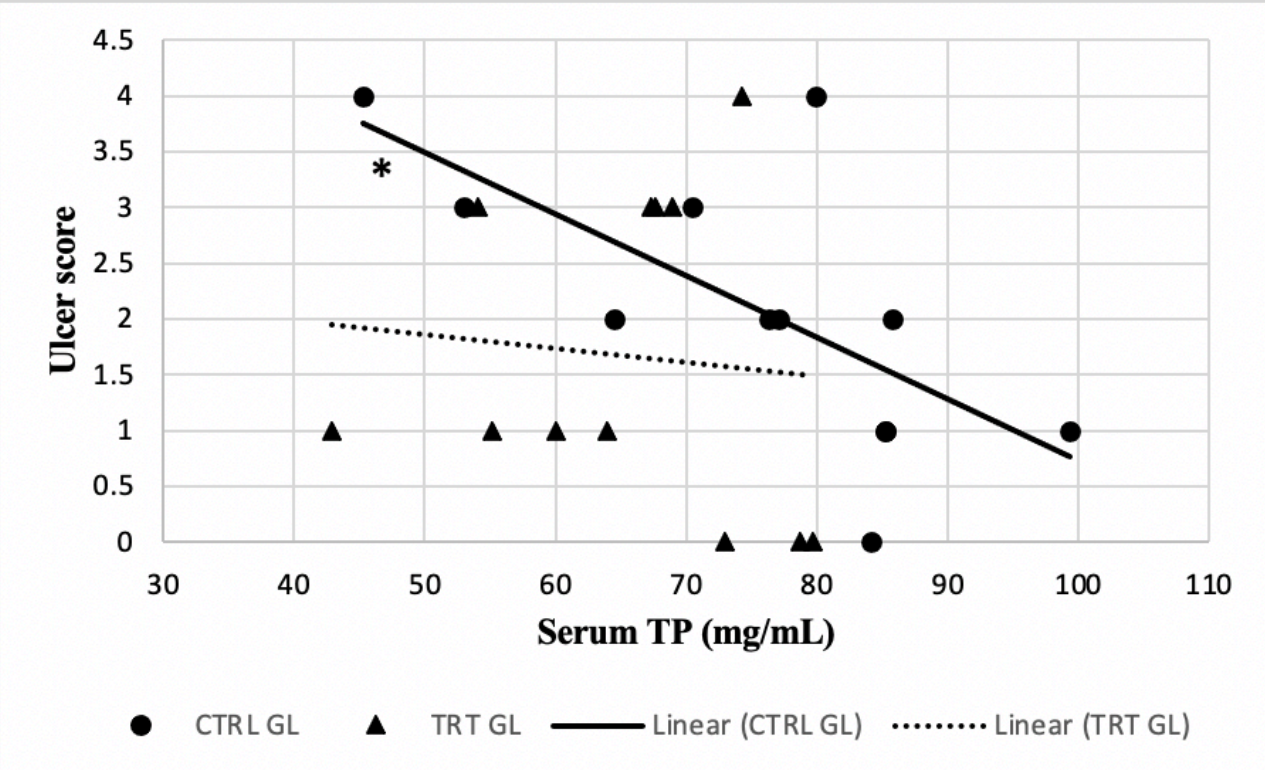

*Indicates significant linear trend $(\mathrm{P}=0.016)$

$$
\begin{gathered}
y=-0.0553 x+6.2617 \\
R^{2}=0.456
\end{gathered}
$$

\section{Discussion}

A negative correlation was found between salivary adenosine deaminase (ADA) and GL ulcer scores of the TRT group, meaning ADA concentrations were increased in TRT horses with lower GL ulcer scores. This contradicts findings in studies observing salivary analytes in swine, in which ADA concentrations were increased by acute stress or pathologic conditions (Contreras-Aguilar et al., 2019; Tecles et al., 2018, 2017).

However, it has been found that ADA can have either pro- or anti-inflammatory effects, depending on immune status, due to differences in response to various receptors. It is possible that levels of ADA are increased in horses with lower GL scores due to working as an anti-inflammatory agent. There are cases in humans in which decreased ADA concentrations are associated with the progression of disease, such as in some cancers. 
This is most likely by mechanism of neutralizing the upregulated purine and DNA metabolism, and the effects on tissues will depend on the length of time that has passed from the initial injury (Bagheri et al., 2019).

Salivary total antioxidant capacity (TAC) concentrations had a negative correlation with the GL scores of the horses in the TRT group. The negative correlation is especially unprecedented in the TRT group, as the particular polysaccharide in the supplement has been shown to reduce free radicals in the body, acting as an antioxidant (Brindzova et al., 2008). This contradictory result may be due to the salivary sampling method, or the use of a low of a molecular weight beta-glucan (Błaszczyk et al., 2015). A positive correlation was present between serum TAC concentrations and SQ ulcer scores in the CTRL group. The involvement of free radicals is known to be involved in the genesis of gastric ulcers as well as other malignancies of the GI tract (Tandon et al., 2004). Free radical accumulation is modulated by antioxidant enzymes, and when these factors are imbalanced the reactive oxygen species (ROS) cause tissue damage.

Serum ADA levels correlated positively with GL ulcer scores of TRT horses such that as ADA concentrations increased, the GL ulcer scores did as well. ADA concentration increases with various diseases, which may be due to its macrophage and monocyte lineage, reflecting the immune response (Bagheri et al., 2019). In humans with GI disease, serum ADA levels were elevated, suggesting a fractional role of activated Tcell response in the disease pathophysiology (Beyazit et al., 2012). Increased ADA activity was detected in the GI tract of rats following inflammatory insult of the 
gastrointestinal (GI) tract. Catabolic degradation of adenosine by ADA may result in impairment of immune modulation by adenosine, resulting in the worsening of inflammation and tissue injury (Antonioli et al., n.d.; Vieira et al., 2014). Adenosine has the potential to mediate pro-inflammatory and/or anti-inflammatory and immunosuppressant activities in gut diseases in humans and rats, but more research is needed to assess the efficacy of this therapy in equine GI disease.

\section{Conclusion}

Specific salivary and serum analytes correlated variously with ulcers in the SQ and GL regions of the equine stomach. Of the salivary analytes, ADA and TAC showed relationships with ulcer scores. The GL ulcer scores of the TRT group correlated negatively with salivary ADA concentrations, potentially due to the effect of time from initial tissue injury. Additionally, the GL scores of the TRT group correlated negatively with salivary TAC concentrations, possibly due to the oxidative stress occurring in the damaged tissue. Of the serum analytes, ADA, TAC and TP showed relationships with ulcer scores. The GL scores of the TRT group correlated positively with serum ADA concentrations, likely due to an immune and inflammatory response. The SQ scores of the CTRL group correlated positively with serum TAC concentrations, posing an unexpected relationship that may be due to acute rather than chronic ulcerations. The GL scores of the CTRL group correlated negatively with serum TP concentrations, potentially due to low hydration levels of horses post-fasting and water withdrawal. 


\section{CHAPTER FOUR}

SUMMARY

The results of this study indicate that polysaccharide supplementation at $10 z$ twice daily over a 6-week period does not have an effect on ulcer scores in the SQ or GL region of the equine stomach in a fasting-induced model. It is possible that the induced model is not the most proficient way of assessing the efficacy of the supplement as both the TRT and CTRL groups healed at the same rate over the 6-week period. In addition, the lack of common risk factors such as intermittent forage availability, exercise, and transportation may have contributed to high natural healing rates. The inconsistent improvement of scores between the SQ and GL ulcers further supports the novel concept of tailoring treatment to the region of ulceration, as the pathophysiology and healing rates of the two tissue types differ greatly. Further, predisposition of common areas to ulceration due to anatomical configuration of the stomach is an important factor to consider for treatment. Consistent with literature, there was an average ventral $\mathrm{pH}$ of around 3. Due to the horses' fasted state, cardiac $\mathrm{pH}$ averaged around 4, though under normal conditions it is typically around 7. As the ulcerogenic threshold for SQ ulceration has been defined at a $\mathrm{pH}$ of 4, exploration of diagnostic or screening methods outside of endoscopies should be pursued due to the procedure's required fasting.

There were correlations of several salivary and serum analytes with ulcerations of various regions in the equine stomach. Of the salivary analytes, ADA and TAC showed relationships with ulcer scores. The GL ulcer scores of the TRT group correlated negatively with salivary ADA concentrations, potentially due to the effect of time from 
initial tissue injury. Additionally, the GL scores of the TRT group correlated negatively with salivary TAC concentrations, possibly due to the oxidative stress occurring in the damaged tissue. Of the serum analytes, ADA, TAC and TP showed relationships with ulcer scores. The GL scores of the TRT group correlated positively with serum ADA concentrations, likely due to an immune and inflammatory response. The SQ scores of the CTRL group correlated positively with serum TAC concentrations, posing an unexpected relationship that may be due to acute rather than chronic ulcerations. The GL scores of the CTRL group correlated negatively with serum TP concentrations, potentially due to low hydration levels of horses post-fasting and water withdrawal.

The data represented in this study provide a valuable basis for the continued pursuit of knowledge concerning the efficacy of polysaccharide supplementation on naturally occurring ulcers, as well as developing a less invasive diagnostic or screening technique for detecting equine gastric ulcers. Additional research involving a noninduced model and non-fasted collection of biological samples may further define the effect of polysaccharide supplementation on equine gastric ulcers and provide a more accurate representation of the horse's biochemical status. 


\section{REFERENCES}

Al-Bayaty, F., Abdulla, M., Darwish, P., 2009. Evaluation of hyaluronate anti-ulcer activity against gastric mucosal injury. Afr. J. Pharm. Pharmacol. 5, 23-30. https://doi.org/10.5897/AJPP10.211

Allen, A., Flemstrom, G., 2005. Gastroduodenal mucus bicarbonate barrier: protection against acid and pepsin. American Journal of Physiology-Cell Physiology C1C19.

Alqasoumi, S., Al-Yahya, M., Alhowiriny, T., Rafatullah, S., 2008. Gastroprotective effect of radish "Raphanus Sativus” L. on experimental Gastric ulcer models in rats. FARMACIA 2.

Andrews, F., 1999. Recommendations for the diagnosis and treatment of equine gastric ulcer syndrome (EGUS): The Equine Gastric Ulcer Council. Equine Vet. Educ. 11, 262-272. https://doi.org/10.1111/j.2042-3292.1999.tb00961.x

Andrews, F., Nadeau, J., 1999. Clinical syndrome of gastric ulceration in foals and mature horses. Equine Vet. J. Suppl. 29, 30-3. https://doi.org/10.1111/j.20423306.1999.tb05165.x

Andrews, F.M., 2008. Poor performance: Can heartburn slow a horse? Equine Vet. Educ. 20, 125-126. https://doi.org/10.2746/095777308X284000

Andrews, F.M., Reinemeyer, C.R., Longhofer, S., 2009. Effects of Top-Dress Formulations of Suxibuzone and Phenylbutazone on Development of Gastric Ulcers in Horses [WWW Document]. ResearchGate. URL https://www.researchgate.net/publication/40804936_Effects_of_Top- 
Dress_Formulations_of_Suxibuzone_and_Phenylbutazone_on_Development_of_ Gastric_Ulcers_in_Horses (accessed 9.16.20).

Andrews, F.M., Sifferman, R.L., Bernard, W., Hughes, F.E., Holste, J.E., Daurio, C.P., Alva, R., Cox, J.L., 1999. Efficacy of omeprazole paste in the treatment and prevention of gastric ulcers in horses. Equine Vet. J. 31, 81-86. https://doi.org/10.1111/j.2042-3306.1999.tb05176.x

Antonioli, L., Fornai, M., Colucci, R., Awwad, O., Ghisu, N., Settimo, F.D., Motta, C.L., Natale, G., Duranti, E., Virdis, A., B1, C., B1, P.C., n.d. Jpet \# 1712231.

Argenzio, R.A., 1999. Comparative pathophysiology of nonglandular ulcer disease: a review of experimental studies. Equine Vet. J. 31, 19-23. https://doi.org/10.1111/j.2042-3306.1999.tb05163.x

Bagheri, S., Saboury, A.A., Haertlé, T., 2019. Adenosine deaminase inhibition. Int. J. Biol. Macromol. 141, 1246-1257. https://doi.org/10.1016/j.ijbiomac.2019.09.078 Barr, B., 2001. Gastric ulcer prophylaxis in the critically ill equine neonate, in: Recent Advances in Equine Neonatal Care. International Veterinary Information Service, Ithica, NY.

Begg, L., O'Sullivan, C., 2003. The prevalence and distribution of gastric ulceration in 345 racehorses. Aust. Vet. J. 81, 199-201. https://doi.org/10.1111/j.17510813.2003.tb11469.x

Beil, W., Birkholz, C., Kf, S., 1995. Effects of flavonoids on parietal cell acid secretion, gastric mucosal prostaglandin production and Helicobacter pylori growth. Arzneimittelforschung. 45, 697-700. 
Bell, R.J.W., Kingston, J.K., Mogg, T.D., Perkins, N.R., 2007. The prevalence of gastric ulceration in racehorses in New Zealand. N. Z. Vet. J. 55, 13-18. https://doi.org/10.1080/00480169.2007.36729

Berschneider, H.M., Blikslager, A.T., Roberts, M.C., 1999. Role of duodenal reflux in nonglandular gastric ulcer disease of the mature horse. Equine Vet. J. 31, 24-29. https://doi.org/10.1111/j.2042-3306.1999.tb05164.x

Beyazit, Y., Koklu, S., Tas, A., Purnak, T., Sayilir, A., Kurt, M., Turhan, T., Celik, T., Suvak, B., Torun, S., Akbal, E., 2012. Serum adenosine deaminase activity as a predictor of disease severity in ulcerative colitis. J. Crohns Colitis 6, 102-107. https://doi.org/10.1016/j.crohns.2011.07.010

Birkmann, K., Junge, H.K., Maischberger, E., Eser, M.W., Schwarzwald, C.C., 2014. Efficacy of Omeprazole Powder Paste or Enteric-Coated Formulation in Healing of Gastric Ulcers in Horses. J. Vet. Intern. Med. 28, 925-933. https://doi.org/10.1111/jvim.12341

Błaszczyk, K., Wilczak, J., Harasym, J., Gudej, S., Suchecka, D., Królikowski, T., Lange, E., Gromadzka-Ostrowska, J., 2015. Impact of low and high molecular weight oat beta-glucan on oxidative stress and antioxidant defense in spleen of rats with LPS induced enteritis. Food Hydrocoll. 51, 272-280. https://doi.org/10.1016/j.foodhyd.2015.05.025

Blikslager, A.T., II, N.A.W., Moore, J.N., Mair, T.S., 2017. The Equine Acute Abdomen. John Wiley \& Sons. 
Borne, A.T., MacAllister, C.G., 1993. Effect of sucralfate on healing of subclinical gastric ulcers in foals. J Am Vet Med Assoc 1465-1468.

Boswinkel, M., Ellis, A.D., Sloet van Oldruitehnborgh-Oosterbaan, M.M., 2007. The influence of low versus high fibre haylage diets in combination with training or pasture rest on equine gastric ulceration syndrome (EGUS): Pferdeheilkunde Equine Med. 23, 123-130. https://doi.org/10.21836/PEM20070203

Brindzova, L., Certik, M., Rapta, P., Zalibera, M., Mikulajova, A., Takacsova, M., 2008. Antioxidant activity, beta-glucan and lipid contents of oat varieties. Czech J. Food Sci. - UZPI Czech Repub.

Brunton, L.L., 2000. Agents for control of gastric acidity and treatment of peptic ulcers, in: Goodman and Gilman's the Pharmacological Basis of Therapeutics. McGraw Hill, New York, pp. 897-913.

Buchanan, B., Andrews, F., 2004. Treatment and prevention of equine gastric ulcer syndrome. Vet. Clin. North Am. Equine Pract. 19, 575-97. https://doi.org/10.1016/j.cveq.2003.08.012

Camici, M., Garcia-Gil, M., Tozzi, M.G., 2018. The Inside Story of Adenosine. Int. J. Mol. Sci. 19, 784. https://doi.org/10.3390/ijms19030784

Carney, C.N., Orlando, R.C., Powell, D.W., Dotson, M.M., 1981. Morphologic alterations in early acid-induced epithelial injury of the rabbit esophagus. Lab. Investig. J. Tech. Methods Pathol. 198-208. 
Cg, M., Sj, M., At, B., Ra, P., 1993. Comparison of adverse effects of phenylbutazone, flunixin meglumine, and ketoprofen in horses. J. Am. Vet. Med. Assoc. 202, 7177.

Chameroy, K.A., Nadeau, J.A., Bushmich, S.L., Dinger, J.E., Hoagland, T.A., Saxton, A.M., 2006. Prevalence of non-glandular gastric ulcers in horses involved in a university riding program. J. Equine Vet. Sci. 26, 207-211. https://doi.org/10.1016/j.jevs.2006.03.001

Chen, H., Nie, Q., Xie, M., Yao, H., Zhang, K., Yin, J., Nie, S., 2019. Protective effects of $\beta$-glucan isolated from highland barley on ethanol-induced gastric damage in rats and its benefits to mice gut conditions. Food Res. Int. 122, 157-166. https://doi.org/10.1016/j.foodres.2019.04.011

Cheng, C.L., Koo, M.W.L., 2000. Effects of Centella asiatica on ethanol induced gastric mucosal lesions in rats. Life Sci. 67, 2647-2653. https://doi.org/10.1016/S00243205(00)00848-1

Chien, W., Stevens, C., 1972. Coupled active transport of $\mathrm{Na}$ and $\mathrm{Cl}$ across forestomach epithelium. Am. J. Physiol.-Leg. Content 223, 997-1003. https://doi.org/10.1152/ajplegacy.1972.223.4.997

Clark, C.K., Merritt, A.M., Burrow, J.A., Steible, C.K., 1996. Effect of aluminum hydroxide/magnesium hydroxide antacid and bismuth subsalicylate on gastric $\mathrm{pH}$ in horses. J. Am. Vet. Med. Assoc. 208, 1687-1691.

Contreras, M., Morales, A., García-Amado, M.A., Vera, M.D., Bermúdez, V., Gueneau, P., 2007. Detection of Helicobacter-like DNA in the gastric mucosa of 
Thoroughbred horses. Lett. Appl. Microbiol. 45, 553-557.

https://doi.org/10.1111/j.1472-765X.2007.02227.x

Contreras-Aguilar, M.D., Escribano, D., Martínez-Subiela, S., Martín-Cuervo, M., Lamy, E., Tecles, F., Cerón, J.J., 2019. Changes in saliva analytes in equine acute abdominal disease: a sialochemistry approach. BMC Vet. Res. 15, 187. https://doi.org/10.1186/s12917-019-1933-6

D, H., A, T., 1991. Is there a role for dietary essential fatty acids in gastroduodenal mucosal protection? J. Clin. Gastroenterol. 13 Suppl 1, S72-4. https://doi.org/10.1097/00004836-199112001-00012

da Silva, A.S., Santurio, J.M., Roza, L.F., Bottari, N.B., Galli, G.M., Morsch, V.M., Schetinger, M.R.C., Baldissera, M.D., Stefani, L.M., Radavelli, W.M., Tomasi, T., Boiago, M.M., 2017. Aflatoxins produced by Aspergillus parasiticus present in the diet of quails increase the activities of cholinesterase and adenosine deaminase. Microb. Pathog. 107, 309-312. https://doi.org/10.1016/j.micpath.2017.03.041

Daurio, C.P., Holste, J.E., Andrews, F.M., Merritt, A.M., Blackford, J.T., Dolz, F., Thompson, D.R., 1999. Effect of omeprazole paste on gastric acid secretion in horses. Equine Vet. J. 31, 59-62. https://doi.org/10.1111/j.20423306.1999.tb05171.x

Ding, Q., Nie, S., Hu, J., Zong, X., Li, Q., Xie, M., 2017. In vitro and in vivo gastrointestinal digestion and fermentation of the polysaccharide from Ganoderma etrum. Food Hydrocolloids 646-655. 
Dionne, R.M., Vrins, A., Doucet, M.Y., Pare, J., 2003. Gastric Ulcers in Standardbred Racehorses: Prevalence, Lesion Description, and Risk Factors. J. Vet. Intern. Med. 17, 218-222. https://doi.org/10.1111/j.1939-1676.2003.tb02437.x

Doucet, M.Y., Vrins, A.A., Dionne, R., Alva, R., Ericsson, G., 2003. Efficacy of a paste formulation of omeprazole for the treatment of naturally occurring gastric ulcers in training standardbred racehorses in Canada. Can. Vet. J. 44, 581-585.

Dukti, S.A., Perkins, S., Murphy, J., Barr, B., Boston, R., Southwood, L.L., Bernard, W., 2006. Prevalence of gastric squamous ulceration in horses with abdominal pain. Equine Vet. J. 38, 347-349. https://doi.org/10.2746/042516406777749164

Fellenius, E., Berglindh, T., Sachs, G., Olbe, L., Elander, B., Sjöstrand, S.-E., Wallmark, B., 1981. Substituted benzimidazoles inhibit gastric acid secretion by blocking $(\mathrm{H}++\mathrm{K}+)$ ATPase. Nature 290, 159-161. https://doi.org/10.1038/290159a0

Ferrucci, F., Zucca, E., Croci, C., Di Fabio, V., Ferro, E., 2003. Treatment of gastric ulceration in 10 standardbred racehorses with a pectin-lecithin complex. Vet. Rec. 152, 679-681. https://doi.org/10.1136/vr.152.22.679

Fiege, K., Furst, A., Eser, M.W., 2002. Effects of housing, feeding, and use on equine health with emphasis on respiratory and gastrointestinal disease. Schweiz. Arch. Tierrheilkd 348-355.

Flemstrong, G., 1994. Gastric and duodenal mucosal secretion of bicarbonate, in: Physiology of the Gastrointestinal Tract. Raven Press, New York, pp. 1285-1309. Fox, J.G., 2002. The non-H pylori helicobacters: their expanding role in gastrointestinal and systemic diseases. Gut 50, 273-283. https://doi.org/10.1136/gut.50.2.273 
Frank, N., Andrews, F., Elliott, S., Lew, J., 2005. Effects of dietary oils on the development of gastric ulcers in mares. Am. J. Vet. Res. 66, 2006-11. https://doi.org/10.2460/ajvr.2005.66.2006

Franklin, S.H., Brazil, T.J., Allen, K.J., 2008. Poor performance associated with equine gastric ulceration syndrome in four Thoroughbred racehorses. Equine Vet. Educ. 20, 119-124. https://doi.org/10.2746/095777308X282363

Fredholm, B.B., 2007. Adenosine, an endogenous distress signal, modulates tissue damage and repair. Cell Death Differ. 14, 1315-1323. https://doi.org/10.1038/sj.cdd.4402132

Grant, H.W., Palmer, K.R., Kelly, R.W., Wilson, N.H., Misiewicz, J.J., 1988. Dietary linoleic acid, gastric acid, and prostaglandin secretion. Gastroenterology 94, 955959. https://doi.org/10.1016/0016-5085(88)90553-7

Grisham, M.B., 1994. Oxidants and free radicals in inflammatory bowel disease. Lancet $859-861$.

Guo, H., Gong, M., Lu, M., Lu, M.Y., Wang, L., Zhang, Q., Lin, S., 2018. Phenolic profiles, B-glucan contents, and antioxidant capacities of colored Qingke (Tibetan hulless barley) cultivars. Journal of Cereal Science 69-75.

Guslandi, M., 1985. Ulcer-healing drugs and endogenous prostaglandins. Int. J. Clin. Pharmacol. 23, 398-402.

Hall, J., 2000. Diseases of the stomach, in: Textbook of Veterinary Internal Medicine: Diseases of the Dog and Cat. WB Saunders, Philadelphia, pp. 1154-1182. 
Hartmann, A.M., Frankeny, R.L., 2003. A preliminary investigation into the association between competition and gastric ulcer formation in non-racing performance horses. J. Equine Vet. Sci. 23, 560-561. https://doi.org/10.1016/j.jevs.2003.11.007

Hellings, I.R., Larsen, S., 2014. ImproWin ${ }^{\circledR}$ in the treatment of gastric ulceration of the squamous mucosa in trotting racehorses. Acta Vet. Scand. 56, 13. https://doi.org/10.1186/1751-0147-56-13

Hepburn, R., 2005. Endoscopic examination of the squamous and glandular gastric mucosa in sport and leisure horses: 684 horses, in: Proc 11th Interntational Equine Colic Research Symposium. Presented at the Proc 11th International Equine Colic Research Symposium, 2014.

Hepburn, R.J., Proudman, C., 2014. Treatment of ulceration of the gastric glandular mucosa: Retrospective evaluation of omeprazole and sucralfate combination therapy in 204 sport and leisure horses. Presented at the Proc 11th International Equine Colic Research Sympo- sium, p. 108.

Hewetson, M., Cohen, N.D., Love, S., Buddington, R.K., Holmes, W., Innocent, G.T., Roussel, A.J., 2006. Sucrose Concentration in Blood: A New Method for Assessment of Gastric Permeability in Horses with Gastric Ulceration. J. Vet. Intern. Med. 20, 388-394. https://doi.org/10.1111/j.1939-1676.2006.tb02873.x Holland, P.S., Ruoff, W.W., Brumbaugh, G.W., Brown, S.A., 1997. Plasma pharmacokinetics of ranitidine $\mathrm{HCl}$ in adult horses. J Vet Pharmacol Ther 145152. 
Huff, N.K., Auer, A.D., Garza, F., Keowen, M.L., Kearney, M.T., McMullin, R.B., Andrews, F.M., 2012. Effect of Sea Buckthorn Berries and Pulp in a Liquid Emulsion on Gastric Ulcer Scores and Gastric Juice pH in Horses. J. Vet. Intern. Med. 26, 1186-1191. https://doi.org/10.1111/j.1939-1676.2012.00975.x

Husted, L., Jensen, T.K., Olsen, S.N., Mølbak, L., 2010. Examination of equine glandular stomach lesions for bacteria, including Helicobacter spp by fluorescence in situ hybridisation. BMC Microbiol. 10, 84. https://doi.org/10.1186/1471-2180-10-84

Husted, L., Sanchez, L.C., Baptiste, K.E., Olsen, S.N., 2009. Effect of a feed/fast protocol on $\mathrm{pH}$ in the proximal equine stomach. Equine Vet. J. 41, 658-662. https://doi.org/10.2746/042516409X416431

Husted, L., Sanchez, L.C., Olsen, S.N., Baptiste, K.E., Merritt, A.M., 2008. Effect of paddock vs. stall housing on 24 hour gastric $\mathrm{pH}$ within the proximal and ventral equine stomach. Equine Vet. J. 40, 337-341. https://doi.org/10.2746/042516408X284673

Jenkins, C.C., Blackford, J.T., Andrews, F., Frazier, D.L., Mattsson, H., Olovsson, S.-G., Peterson, A., 1992. Duration of antisecretory effects of oral omeprazole in horses with chronic gastric cannulae. Equine Vet. J. 24, 89-92. https://doi.org/10.1111/j.2042-3306.1992.tb04795.x

Johnson, B., Carlson, G., Vatistas, N.J., Nilsson, G., 1994. Investigation of the number and location of gastric ulceration in horses race training submitted to the California Racehorse Postmortem Program, in: Proceedings of the American Association of Equine Practitioners. pp. 123-124. 
Johnson, J.H., Vatistas, N.J., Castro, L., Fischer, T., Pipers, F.S., Maye, D., 2001. Field survey of the prevalence of gastric ulcers in Thoroughbred racehorses and on response to treatment of affected horses with omeprazole paste. Equine Vet Educ 221-224.

Jonsson, H., Egenvall, A., 2006. Prevalence of gastric ulceration in Swedish Standardbreds in race training. Equine Vet. J. 38, 209-213. https://doi.org/10.2746/042516406776866390

Kampa, M., Nistikaki, A., Tsaousis, V., Maliaraki, N., Notas, G., Castanas, E., 2002. A new automated method for the determination of the Total Antioxidant Capacity (TAC) of human plasma, based on the crocin bleaching assay. BMC Clin. Pathol. 2, 3. https://doi.org/10.1186/1472-6890-2-3

Kassir, Z.A., 1985. Endoscopic controlled trial of four drug regimens in the treatment of chronic duodenal ulceration. Ir. Med. J. 78: 153-6.

Koeller, G., 2010. Concentration of mukus in gastric juice in normal adult horses withold feed after oral application of Pronutrin. Pferdeheilkunde 186-190.

Koutroubakis, I.E., Malliaraki, N., Dimoulios, P.D., Karmiris, K., Castanas, E., Kouroumalis, E.A., 2004. Decreased Total and Corrected Antioxidant Capacity in Patients with Inflammatory Bowel Disease. Dig. Dis. Sci. 49, 1433-1437. https://doi.org/10.1023/B:DDAS.0000042242.22898.d9

Kruidenier, L., Verspaget, 2002. Review article: Oxidative stress as a pathogenic factor in inflammatory bowel disease-Radicals or ridiculous? Aliment Pharmacol Ther 1997-2015. 
Kumar, V., Sharma, A., 2009. Adenosine: An endogenous modulator of innate immune system with therapeutic potential. Eur. J. Pharmacol. 616, 7-15. https://doi.org/10.1016/j.ejphar.2009.05.005

Lancaster-Smith, M.J., Jaderberg, M.E., Jackson, D.A., 1991. Ranitidine in the treatment of non-steroidal anti-inflammatory drug associated gastric and duodenal ulcers. Gut 32, 252-255. https://doi.org/10.1136/gut.32.3.252

Langmead, L., Feakins, R.M., Goldthorpe, S., Holt, H., Tsironi, E., Silva, A.D., Jewell, D.P., Rampton, D.S., 2004. Randomized, double-blind, placebo-controlled trial of oral aloe vera gel for active ulcerative colitis. Aliment. Pharmacol. Ther. 19, 739747. https://doi.org/10.1111/j.1365-2036.2004.01902.x

Lans, C., Turner, N., Brauer, G., Lourenco, G., Georges, K., 2006. Ethnoveterinary medicines used for horses in Trinidad and in British Columbia, Canada. J. Ethnobiol. Ethnomedicine 2, 31. https://doi.org/10.1186/1746-4269-2-31

Lanza, F.L., 1989. A review of mucosal protection by synthetic prostaglandin E analogs against injury by non-steroidal anti-inflammatory agents. Scand. J. Gastroenterol. Suppl. 163, 36-43. https://doi.org/10.3109/00365528909091173

le Jeune, S.S., Nieto, J.E., Dechant, J.E., Snyder, J.R., 2009. Prevalence of gastric ulcers in Thoroughbred broodmares in pasture: A preliminary report. Vet. J. 181, 251255. https://doi.org/10.1016/j.tvj1.2008.03.020

Lester, G.D., Robertson, I.D., Secombe, C., 2007. Risk factors for gastric ulceration in Thoroughbred racehorses. Presented at the Proceedings of the 53rd Annual 
Convention of the American Association of Equine Practitioners, Orlando, FL, USA, p. 529.

Linden, A.V., Eltzschig, H.K., 2007. Role of pulmonary adenosine during hypoxia: extracellular generation, signaling and metabolism by surface adenosine deaminase/CD26. Expert Opin. Biol. Ther. 7, 1437-1447.

https://doi.org/10.1517/14712598.7.9.1437

Liu, H., Xia, Y., 2015. Beneficial and detrimental role of adenosine signaling in diseases and therapy. J. Appl. Physiol. 119, 1173-1182. https://doi.org/10.1152/japplphysiol.00350.2015

Lj, W., Df, G., 1985. Gastrointestinal symptoms during exercise in Enduro athletes: prevalence and speculations on the aetiology. N. Z. Med. J. 98, 644-646.

Lorenzo-Figueras, M., Merritt, A.M., 2002. Effects of exercise on gastric volume and pH in the proximal portion of the stomach of horses. ResearchGate 1481-1487. https://doi.org/10.2460/ajvr.2002.63.1481

Luthersson, N., Nielsen, K.H., Harris, P., Parkin, T.D.H., 2009a. The prevalence and anatomical distribution of equine gastric ulceration syndrome (EGUS) in 201 horses in Denmark. Equine Vet. J. 41, 619-624.

https://doi.org/10.2746/042516409X441910

Luthersson, N., Nielsen, K.H., Harris, P., Parkin, T.D.H., 2009b. Risk factors associated with equine gastric ulceration syndrome (EGUS) in 201 horses in Denmark. Equine Vet. J. 41, 625-630. https://doi.org/10.2746/042516409X441929 
Lybbert, T., Gibbs, P., Cohen, N., Scott, B., Sigler, D., 2007. Feeding alfalfa hay to exercising horses reduces the severity of gastric squamous mucosal ulceration., in: Proceedings of the 53rd Annual Convention of the American Association of Equine Practitioners. Orlando, FL, USA, pp. 525-526.

MacAlliser, C.G., Sangiah, S., 1993. Effect of ranitidine on healing of experimentally induced gastric ulcers in ponies. Am J Vet Res 1103-1107.

MacAlliser, C.G., Sangiah, S., Mauromoustakos, A., 1992. Effect of a histamine H2 type receptor antagonist (WY 45, 727) on the healing of gastric ulcers in ponies. J Vet Intern Med 271-275.

Malfertheiner, P., Chan, F.K., McColl, K.E., 2009. Peptic ulcer disease. The Lancet 374, 1449-1461. https://doi.org/10.1016/S0140-6736(09)60938-7

Malliaraki, N., Mpliamplias, D., Kampa, M., Perakis, K., Margioris, A.N., Castanas, E., 2003. Total and corrected antioxidant capacity in hemodialyzed patients. BMC Nephrol. 4, 4. https://doi.org/10.1186/1471-2369-4-4

Mandel, K.G., Bertram, T.A., Eichhold, M.K., Pepple, S.C., Doyle, M.J., 1994. Fatty Acid-mediated Gastroprotection Does Not Correlate with Prostaglandin Elevation in Rats Exposed to Various Chemical Insults. Vet. Pathol. 31, 679-688. https://doi.org/10.1177/030098589403100608

Martineau, H., Thompson, H., Taylor, D., 2009. Pathology of gastritis and gastric ulceration in the horse. Part 1: Range of lesions present in 21 mature individuals. Equine Vet. J. 41, 638-644. https://doi.org/10.2746/042516409X464816 
McClure, S.R., Glickman, L.T., Glickman, N.W., 1999. Prevalence of gastric ulcers in show horses. Journal of the American Veterinary Medical Association 11301133.

McDonnell, S.M., 2008. Practical review of self-mutilation in horses. Anim. Reprod. Sci., Special Issue: Proceedings of the 5th International Symposium on Stallion Reproduction 107, 219-228. https://doi.org/10.1016/j.anireprosci.2008.04.012

Merritt, A.M., 2009. Appeal for proper usage of the term 'EGUS': Equine gastric ulcer syndrome. Equine Vet. J. 41, 616-616. https://doi.org/10.2746/042516409X454574

Merritt, A.M., Sanchez, L.C., Burrow, J.A., Church, M., Ludzia, S., 2003. Effect of GastroGard and three compounded oral omeprazole preparations on $24 \mathrm{~h}$ intragastric $\mathrm{pH}$ in gastrically cannulated mature horses. Equine Vet. J. 35, 691695. https://doi.org/10.2746/042516403775696339

Mesa, F.L., Aneiros, J., Cabrera, A., Bravo, M., Caballero, T., Revelles, F., n.d. Antiproliferative effect of topic hyaluronic acid gel. Study in gingival biopsies of patients with periodontal disease 7 .

Moreno, E., Canet, J., Gracia, E., Lluis, J., Mallol, J., Canela, E., Cortes, A., Casado, V., 2018. Molecular evidence of adenosine deaminase linking adenosine A2Areceptor and CD26 proteins. Pharmacol 106.

Murray, M.J., 2017. Diseases of the Stomach, in: The Equine Acute Abdomen. John Wiley \& Sons, Ltd, pp. 663-672. https://doi.org/10.1002/9781119063254.ch50 
Murray, M.J., 1996. Effects of intermittent feed deprivation, intermittent feed deprivation with ranitidine administration, and stall confinement with ad libitum access to hay on gastric ulceration in horses. - Abstract - Europe PMC [WWW Document]. URL https://europepmc.org/article/med/8915437 (accessed 6.1.20).

Murray, M.J., 1992. Gastric ulceration in horses: 91 cases (1987-1990) 117-120.

Murray, M.J., 1991. The pathogenesis and prevalence of gastric ulceration in foals and horses. Vet Med 815-819.

Murray, M.J., Grady, T.C., 2002. The effect of a pectin-lecithin complex on prevention of gastric mucosal lesions induced by feed deprivation in ponies. Equine Vet. J. 34, 195-198. https://doi.org/10.2746/042516402776767268

Murray, M.J., Grodinsky, C., 1992. The effects of famotidine, ranitidine and magnesium hydroxide/aluminium hydroxide on gastric fluid $\mathrm{pH}$ in adult horses. Equine Vet. J. 24, 52-55. https://doi.org/10.1111/j.2042-3306.1992.tb04773.x

Murray, M.J., Grodinsky, C., Anderson, C.W., Radue, P.F., Schmidt, G.R., 1989. Gastric ulcers in horses: a comparison of endoscopic findings in horses with and without clinical signs. Equine Vet. J. 21, 68-72. https://doi.org/10.1111/j.20423306.1989.tb05659.x

Murray, M.J., Haven, M.L., Eichorn, E.S., Zhang, D., Eagleson, J., Hickey, G.J., 1997. Effects of omeprazole on healing of naturally-occurring gastric ulcers in Thoroughbred racehorses. Equine Vet. J. 29, 425-429. https://doi.org/10.1111/j.2042-3306.1997.tb03153.x 
Murray, M.J., Nout, Y.S., Ward, D.L., 2001. Endoscopic Findings of the Gastric Antrum and Pylorus in Horses: 162 Cases(1996-2000). J. Vet. Intern. Med. 15, 401-406. https://doi.org/10.1111/j.1939-1676.2001.tb02336.x

Murray, M.J., Schusser, G.F., 1993. Measurement of 24-h gastric pH using an indwelling $\mathrm{pH}$ electrode in horses unfed, fed, and treated with ranitidine. Equine veterinary journal 417-421.

Murray, M.J., Schusser, G.R., Pipers, F.S., Gross, S.J., 1996. Factors associated with gastric lesions in Thoroughbred racehorses. Equine Vet. J. 28, 368-374. https://doi.org/10.1111/j.2042-3306.1996.tb03107.x

Nadeau, J.A., Andrews, F.M., Mathew, A.G., Argenzio, R.A., Blackford, J.T., Sohtell, M., Saxton, A.M., 2000. Evaluation of diet as a cause of gastric ulcers in horses. Am. J. Vet. Res. 61, 784-790. https://doi.org/10.2460/ajvr.2000.61.784

Nadeau, J.A., Andrews, F.M., Patton, C.S., Argenzio, R.A., Mathew, A.G., Saxton, A.M., 2003. Effects of hydrochloric, valeric, and other volatile fatty acids on pathogenesis of ulcers in the nonglandular portion of the stomach of horses. Am. J. Vet. Res. 64, 413-417. https://doi.org/10.2460/ajvr.2003.64.413

Nicol, C.J., Davidson, H.P.D., Harris, P.A., Waters, A.J., Wilson, A.D., 2002. Study of crib-biting and gastric inflammation and ulceration in young horses. Vet. Rec. 151, 658-662. https://doi.org/10.1136/vr.151.22.658

Niedźwiedź, A., Kubiak, K., Nicpoń, J., 2013. Endoscopic findings of the stomach in pleasure horses in Poland. Acta Vet. Scand. 55, 45. https://doi.org/10.1186/1751$0147-55-45$ 
Nieto, J.E., Snyder, J.R., Beldomenico, P., Aleman, M., Kerr, J.W., Spier, S.J., 2004. Prevalence of gastric ulcers in endurance horses - a preliminary report. Vet. J. 167, 33-37. https://doi.org/10.1016/j.tvj1.2003.09.005

Nieto, J.E., Snyder, J.R., Vatistas, N.J., Jones, J.H., 2009. Effect of gastric ulceration on physiologic responses to exercise in horses 70,9 .

O’Conner, M.S., Steiner, J.M., Roussel, A.J., Williams, D.A., Meddings, J.B., Pipers, F., Cohen, N.D., 2004. Evaluation of urine sucrose concentration for detection of gastric ulcers in horses. Am. J. Vet. Res. 65, 31-39. https://doi.org/10.2460/ajvr.2004.65.31

Oliveira, A., Luz, B., Werner, M., Lacomini, M., Cordeiro, L., Cipriani, T., 2018. Gastroprotective activity of a pectic polysaccharide fraction obtained from infusion of Sedum dendroideum leaves 7-12.

Orlando, R.C., 1991. Textbook of gastroenterology, in: Textbook of Gastroenterology. JB Lippincort Co., Philadelphia, pp. 1123-1147.

Orsini, J.A., Hackett, E.S., Grenager, N., 2009. The Effect of Exercise on Equine Gastric Ulcer Syndrome in the Thoroughbred and Standardbred Athlete. J. Equine Vet. Sci. 29, 167-171. https://doi.org/10.1016/j.jevs.2009.01.006

Park, J., Gupta, R.S., 2013. Adenosine Metabolism, Adenosine Kinase, and Evolution, in: Masino, S., Boison, D. (Eds.), Adenosine: A Key Link between Metabolism and Brain Activity. Springer, New York, NY, pp. 23-54. https://doi.org/10.1007/9781-4614-3903-5_2 
Pellegrini, F.L., 2005. Results of a large-scale necroscopic study of equine colonic ulcers.

J. Equine Vet. Sci. 25, 113-117. https://doi.org/10.1016/j.jevs.2005.02.008

Plumb, D.C., 2002. Veterinary drug handbook, 4th ed. Iowa State Press.

Rabuffo, T., Orsini, J., Hackett, E., Engiles, J., Norman, T., Boston, R., 2002.

Associations between age or sex and prevalence of gastric ulceration in

Standardbred racehorses in training. J. Am. Vet. Med. Assoc. 221, 1156-9.

https://doi.org/10.2460/javma.2002.221.1156

Ralevic, V., Burnstock, G., 1998. Receptors for purines and pyrimidine. Pharmacol Rev 413-492.

Rodriguez-Stanley, S., 2006. Effect of esophageal acid and prophylactic rabeprozole on performance in runners. Medicine and science in sports and exercise 1659-1665.

Ross, I.N., Bahari, H.M., Turneberg, L.A., 1981. The pH gradient across mucus adherent to rat fundic mucosa in vivo and the effect of potential damaging agents. Gastroenterology 713-718.

Roy, M.-A., Vrins, A., Beauchamp, G., Doucet, M.Y., 2005. Prevalence of Ulcers of the Squamous Gastric Mucosa in Standardbred Horses. J. Vet. Intern. Med. 19, 744750. https://doi.org/10.1111/j.1939-1676.2005.tb02755.x

Sandin, A., Skidell, J., Häggström, J., Nilsson, G., 2000. Postmortem findings of gastric ulcers in Swedish horses older than age one year: a retrospective study of 3715 horses (1924-1996). Equine Vet. J. 32, 36-42.

https://doi.org/10.2746/042516400777612044 
Saracoglu, U., Guven, O., Durak, I., 2005. Adenosine deaminase and 5'-nucleotidase activities in saliva from patients with oral and laryngeal cancer. Oral Dis. 11, 323-325. https://doi.org/10.1111/j.1601-0825.2005.01131.x

Satoh, H., Urushidani, T., 2016. Soluble Dietary Fiber Can Protect the Gastrointestinal Mucosa Against Nonsteroidal Anti-Inflammatory Drugs in Mice. Dig. Dis. Sci. 61, 1903-1914. https://doi.org/10.1007/s10620-016-4086-5

Schepp, W., Steffen, B., Ruoff, H.-J., Schusdziarra, V., Classen, M., 1988. Modulation of rat gastric mucosal prostaglandin E2 release by dietary linoleic acid: Effects on gastric acid secretion and stress-induced mucosal damage. Gastroenterology 95, 18-25. https://doi.org/10.1016/0016-5085(88)90285-5

Scott, D.R., Marcus, E.A., Shirazi-Beechley, 2001. Evidence of Helicobacter infection in the horse, in: Proceedings of the American Society of Microbiologists. Washington, DC, p. 287.

Shimizu, N., Watanabe, T., Arakawa, T., Fujiwara, Y., Higuchi, K., Kuroki, T., 2000. Pentoxifylline Accelerates Gastric Ulcer Healing in Rats: Roles of Tumor Necrosis Factor Alpha and Neutrophils during the Early Phase of Ulcer Healing. Digestion 61, 157-164. https://doi.org/10.1159/000007752

Silen, W., 1987. Gastric mucosal defense and repair, in: Physiology of the Gastrointestinal Tract. pp. 1044-1069.

Slovis, N., 2017. Polysaccharide Treatment Reduces Gastric Ulceration in Active Horses. J. Equine Vet. Sci. 50, 116-120. https://doi.org/10.1016/j.jevs.2016.11.011 
Sundell, G., Nillsson, C., 1986. Structure and function of dog gastric mucosa during and after 2-year treatment with omeprazole. II. Effects on gastric acid secretion and blood leels of gastric hormones. Scand. J. Gastroenterol. Suppl. 82-85.

Sykes, B., Jokisalo, J.M., 2015. Rethinking equine gastric ulcer syndrome: Part 3 Equine glandular gastric ulcer syndrome (EGGUS). Equine Vet. Educ. 27, 372375. https://doi.org/10.1111/eve.12287

Sykes, B.W., Hewetson, M., Hepburn, R.J., Luthersson, N., Tamzali, Y., 2015 a. European College of Equine Internal Medicine Consensus Statement—Equine Gastric Ulcer Syndrome in Adult Horses. J. Vet. Intern. Med. 29, 1288-1299. https://doi.org/10.1111/jvim.13578

Sykes, B.W., Jokisalo, J., Hallowell, G., n.d. Evaluation of a commercial faecal blood test for the diagnosis of gastric ulceration in Thoroughbred racehorses: A preliminary report.

Sykes, B.W., Jokisalo, J.M., 2014. Rethinking equine gastric ulcer syndrome: Part 1 Terminology, clinical signs and diagnosis. Equine Vet. Educ. 26, 543-547. https://doi.org/10.1111/eve.12236

Sykes, B.W., Sykes, K.M., Hallowell, G.D., 2015b. A comparison of three doses of omeprazole in the treatment of equine gastric ulcer syndrome: A blinded, randomised, dose-response clinical trial. Equine veterinary journal 285-290.

Sykes, B. W., Sykes, K.M., Hallowell, G.D., 2014a. A comparison of two doses of omeprazole in the treatment of equine gastric ulcer syndrome: A blinded, 
randomised, clinical trial. Equine Vet. J. 46, 416-421.

https://doi.org/10.1111/evj.12191

Sykes, B. W., Sykes, K.M., Hallowell, G.D., 2014b. A comparison between pre- and post exercise administration of omeprazole in the treatment of equine gastric ulcer syndrome: A blinded, randomised, clinical trial. Equine Vet. J. 46, 422-426. https://doi.org/10.1111/evj.12083

Sykes, B.W., Sykes, K.M., Hallowell, G.D., 2014. Administration of trimethoprimsulphadimidine does not improve healing of glandular gastric ulceration in horses receiving omeprazole: a randomised, blinded, clinical study. BMC Vet. Res. 10, 180. https://doi.org/10.1186/s12917-014-0180-0

Sykes, B.W., Sykes, K.M., Hallowell, G.D., 2014. Efficacy of a Combination of Apolectol, Live Yeast (Saccharomyces cerevisiae [CNCM I-1077]), and Magnesium Hydroxide in the Management of Equine Gastric Ulcer Syndrome in Thoroughbred Racehorses: A Blinded, Randomized, Placebo-Controlled Clinical Trial. J. Equine Vet. Sci. 34, 1274-1278. https://doi.org/10.1016/j.jevs.2014.09.006

Szelnenyi, I., Postious, S., Engler, H., 1989. Evidence for a functional cytoprotective effect produced by antacids in the rat stomach. Eur J Pharmacol 403-406.

Tamzali, Y., 2011. Prevalence of gastric ulcer syndrome in high-level endurance horses. Equine veterinary journal 141-144. 
Tandon, R., Khanna, H., Babu, M., Goel, R., 2004. Oxidative stress and antioxidant status in peptic ulcer and gastric carcinoma. Indian J. Physiol. Pharmacol. 48, $115-8$.

Tecles, F., Contreras-Aguilar, M.D., Martínez-Miró, S., Tvarijonaviciute, A., MartínezSubiela, S., Escribano, D., Cerón, J.J., 2017. Total esterase measurement in saliva of pigs: Validation of an automated assay, characterization and changes in stress and disease conditions. Res. Vet. Sci. 114, 170-176. https://doi.org/10.1016/j.rvsc.2017.04.007

Tecles, F., Rubio, C.P., Contreras-Aguilar, M.D., López-Arjona, M., Martínez-Miró, S., Martínez-Subiela, S., Cerón, J.J., 2018. Adenosine deaminase activity in pig saliva: analytical validation of two spectrophotometric assays. J. Vet. Diagn. Invest. 30, 175-179. https://doi.org/10.1177/1040638717742947

Tielemans, T., Hakanson, R., Sundler, F., 1989. Proliferation of enterochromaffin-like cells in omeprazole-treated hypergastrinemic rats. Gastroenterology 723-729.

Toole, B.P., n.d. Hyaluronate-cell interactions and growth factor regulation of hyaluronate synthesis during limb development. Ciba Found Symp Vol. 143, 1989.

Vatistas, N.J., Sifferman, R.L., Holste, J., Cox, J.L., Pinalto, G., Schultz, K.T., 1999. Induction and maintenance of gastric ulceration in horses in simulated race training. Equine Vet. J. 31, 40-44. https://doi.org/10.1111/j.20423306.1999.tb05167.x 
Vatistas, N.J., Snyder, J.R., Carlson, G., Johnson, B., Arthu, R.M., Thurmond, M., Zhou, H., Lloyd, K.L.K., 2010. Cross-sectional study of gastric ulcers of the squamous mucosa in Thoroughbred racehorses. Equine Vet. J. 31, 34-39. https://doi.org/10.1111/j.2042-3306.1999.tb05166.x

Venner, M., Lauffs, S., Deegen, E., 1999. Treatment of gastric lesions in horses with pectin-lecithin complex. Equine Vet. J. 31, 91-96. https://doi.org/10.1111/j.20423306.1999.tb05178.x

Videla, R., Andrews, F.M., 2009. New Perspectives in Equine Gastric Ulcer Syndrome. Vet. Clin. Equine Pract. 25, 283-301. https://doi.org/10.1016/j.cveq.2009.04.013

Vieira, C., Magalhães-Cardoso, M.T., Ferreirinha, F., Silva, I., Dias, A.S., Pelletier, J., Sévigny, J., Correia-de-Sá, P., 2014. Feed-Forward Inhibition of CD73 and Upregulation of Adenosine Deaminase Contribute to the Loss of Adenosine Neuromodulation in Postinflammatory Ileitis. Mediators Inflamm. 2014, e254640. https://doi.org/10.1155/2014/254640

Wang, X., Yin, J., Zhao, M., Liu, S., Nie, S., Xie, M., 2018. Gastroprotective activity of polysaccharide from Hericium erinaceus against ethanol-induced gastric mucosal lesion and pylorus ligation-induced gastric ulcer, and its antioxidant activities. Carbohydrate Polymers 100-109.

Watson, J., 2002. Gastric ulcers in foals, in: The Five Minute Veterinary Consultant Equine. Williams and Wilkins, Baltimore, pp. 806-807.

Wilson, D.E., 1988. Misoprostol and gastroduodenal mucosal protection (cytoprotection). Postgrad. Med. J. 64 Suppl 1, 7-11. 
Wong, J.-Y., Abdulla, M.A., Raman, J., Phan, C.-W., Kuppusamy, U.R., Golbabapour, S., Sabaratnam, V., 2013. Gastroprotective Effects of Lion's Mane Mushroom Hericium erinaceus (Bull.:Fr.) Pers. (Aphyllophoromycetideae) Extract against Ethanol-Induced Ulcer in Rats. Evid. Based Complement. Alternat. Med. 2013, e492976. https://doi.org/10.1155/2013/492976

Xu, C., Lv, J., Lo, Y.M., Cui, S.W., Hu, X., Fan, M., 2013. Effects of oat $\beta$-glucan on endurance exercise and its anti-fatigue properties in trained rats. Carbohydr. Polym. 92, 1159-1165. https://doi.org/10.1016/j.carbpol.2012.10.023 